\title{
North Atlantic Wind Waves and Wind Stress Fields from Voluntary Observing Ship Data
}

\author{
Sergey K. GuleV* AND Lutz Hasse \\ Institut für Meereskunde, Kiel, Germany
}

(Manuscript received 20 December 1995, in final form 2 September 1997)

\section{ABSTRACT}

\begin{abstract}
On the basis of the collection of individual marine observations available from the Comprehensive OceanAtmosphere Data Set, major parameters of the sea state were evaluated. Climatological fields of wind waves and swell height and period, as well as significant wave height and resultant period are obtained for the North Atlantic Ocean for the period from 1964 to 1993. Validation of the results against instrumental records from National Data Buoy Center buoys and ocean weather station measurements indicate relatively good agreement for wave height and systematic biases in the visually estimated periods that were corrected. Wave age, which is important for wind stress estimates, was evaluated form wave and wind observations. The climatology of wave age indicates younger waves in winter in the North Atlantic midlatitudes and Tropics. Wave age estimates were applied to the calculations of the wind stress using parameterizations from field experiments. Differences between wave-age-based and traditional estimates are not negligible in wintertime in midlatitudes and Tropics where wave-induced stress contributes from $5 \%$ to $15 \%$ to the total stress estimates. Importance of the obtained effects for ocean circulation and climate variability is discussed.
\end{abstract}

\section{Introduction}

Climatology of wind waves is an important indicator of climatology of the sea-air interface in general. However, different climatologies of sea-air interactions usually do not provide wind wave variables with some seldom exceptions (Hastenrath and Lamb 1978; Esbensen and Kushnir 1981; Isemer and Hasse 1985, 1987; Oberhuber 1988; da Silva et al. 1994). The U.S. Navy Marine Climatic Atlas of the World (hereafter MCA) (Naval Oceanography Command Detachment 1981) contains wave height charts based on a limited collection of visual observations, restricted primarily to the period from the 1920-1930s to the late 1960s. Korevaar (1990) produced a comprehensive climate of meteorological variables and waves for the North Sea, based on observations from ships and lightvessels. Some results were obtained from ocean weather station (OWS) data, which are relatively homogeneous and were taken continuously for periods of at least several years at fixed positions (Walden et al. 1970; Rodewald 1972; Rye 1976). During the period from the mid-1970s to the early

\footnotetext{
* Current affiliation: P. Shirshov Institute for Oceanology, Moscow, Russia.
}

Corresponding author address: P. Shirshov Institute of Oceanology, RAS, 23 Krasikova Str./ 36 Nakhimovsky Ave., 117218 Moscow, Russia.

E-mail: rocc@sovam.com 1990s, NOAA Marine Environmental Buoys Program provides instrumental wave measurements at a number of locations along the east and the west coasts of North America and in the Gulf of Mexico. Long-term series of instrumental measurements with shipborne wave recorders were obtained at OWS L and Seven Stones Light Vessel (Carter and Draper 1988; Bacon and Carter 1991, 1993) and show an increase in mean wave height over the North Atlantic midlatitudes, ranging from 0.1 to 0.4 m per decade. Neu (1984) updated 12-h synoptic wave forecast charts, published by the Meteorological and Oceanographic Center (Halifax, Nova Scotia, Canada), for the period 1970-82. Computed $5^{\circ}$ annual anomalies of significant wave heights indicate a pronounced longterm trend, although the rather short time series is inadequate for discussing these trends with confidence. Widely used by sailors and naval engineers, Ocean Wave Statistics (Hogben and Lumb 1967) and Global Wave Statistics (Hogben et al. 1986) contain statistical distributions based on limited visual wave data for 50 and 104 areas of the World Ocean, respectively. At the same time, there were no attempts to update wave data from the Comprehensive Ocean-Atmosphere Data Set (COADS), which provides at present the most complete collection of marine meteorological observations up to 1993.

During the last decade considerable effort was made to produce a number of satellite datasets of wind waves derived from ERS-1, GEOSAT, and TOPEX/Poseidon (Mognard et al. 1983; Chelton et al. 1990; Tournadre 
and Ezraty 1990; Campbell et al. 1994; Bruning et al. 1994; Young and Holland 1995; Katsaros 1996). These data give very complete coverage of the ocean by measurements of surface elevation, which results from both sea and swell. However, satellite observations are still restricted in time by several years and need to be validated against alternative sources of information and intercompared to each other (Cotton and Carter 1994) and to model products (Bauer et al. 1992). There is a considerable demand for independent estimates of wave variables from the model side. A number of wave simulations and hindcasts with different wind wave, general circulation, and assimilation models need global- or individual basin-scale wave fields for validation (U.S. Navy 1983; de las Heras and Janssen 1992; Weber et al. 1993; Weber 1994; Khandekar et al. 1994; Sterl et al. 1997, manuscript submitted to J. Geophys. Res.).

During the last 30 years strong evidence of the influence of the sea state on wind stress on the sea surface has been found. A number of special field experiments, like JONSWAP (Hasselmann et al. 1973), MARSEN (Geernaert et al. 1986), Lake Ontario (Donelan 1982), HEXOS (Smith et al. 1992), SWADE (Katsaros et al. 1993), Gulf of Alaska (Juszko et al. 1995), and the laboratory experiments of Toba et al. (1990) demonstrated that the roughness of sea surface and therefore the drag coefficient appear to be a function of wave age, although some field measurements reject this dependence (Yelland and Taylor 1996). The physics of the interaction between the wind and wave fields has been developed in theoretical works of Kitaigorodskii (1973), Janssen (1989, 1991), Chalikov and Makin (1991), Perrie and Wang (1995), and others. At the same time, these experimental and theoretical results were not applied yet to the wind stress climatologies, based on voluntary observing ships (VOS) data. In this study we update wind wave data from the COADS collection of individual marine observations in the North Atlantic in order to produce the climatology of wind waves to be compared with in situ observations at a few locations. Long-term observations of wave parameters offer the possibility to compute wind stress, based on its dependence on the sea state, and to determine whether this effect is important for the climatological forcing fields computed mostly using traditional parameterizations (Smith 1980; Large and Pond 1981).

\section{Data processing}

In this study we used individual observations from the COADS. Data for the period 1950-79 were taken from the COADS Release 1 in the form of compressed marine reports (CMR-5) (Slutz et al. 1985). For the period 1980-93 COADS Release 1a provides long marine reports (LMR) (Woodruff et al. 1993; NCAR 1993). Individual CMR and LMR contain in coded form a number of wave parameters, taken visually by VOS with different degrees of accuracy:
1) wave height $\left(h_{w}\right)$ with reported accuracy of $0.5 \mathrm{~m}$

2) wave period $\left(p_{w}\right)$ with reported accuracy of $2 \mathrm{~s}$ for periods greater than $5 \mathrm{~s}$ and unique code for the periods less than $5 \mathrm{~s}$

3) wave direction $\left(d_{w}\right)$ with reported accuracy of 10 deg

4) swell height $\left(h_{s}\right)$ given as wave height

5) swell period $\left(p_{s}\right)$ given as wave period

6) swell direction $\left(d_{s}\right)$ given as wave direction

7) wave period $\left(p_{w}\right)$ in seconds with reported accuracy of $1 \mathrm{~s}$

8) swell period $\left(p_{s}\right)$ in seconds with reported accuracy of $1 \mathrm{~s}$

9) second most significant swell direction

10) second most significant swell height

11) second most significant swell period.

All individual reports were decoded to obtain physical values of the parameters. COADS swell period codes were changed in 1968, and this change might not have been accepted simultaneously by all nations and ship owners, and is hardly detectable. There is a pronounced peak of swell periods in 1968-69 at many locations because the new codes yield swell nearly twice as long as the old codes, and even a small contribution of the incorrectly reported periods can cause a considerable increase of the values for 1969. We tried to break down all reports into the contributions from different nations, using the so-called country code. Most of the nations that reported a significant number of observations indicate this peak, with the exception for France and the former Soviet Union. Thus, we decided to exclude swell periods for 1969 from our analysis. First, we made a quality inspection of the data, according to the quality flags, also available from COADS CMR and LMR. An additional quality check was based on some logical conclusions and consideration of the other variables. For example, some reports from northern areas give simultaneously considerable ice coverage and high waves. In other cases, there is a sharp disagreement between the period, wave height, and wind speed. Special attention has been paid to the nighttime, when the number of such suspicious reports increases. Some nations that contributed reports to the COADS collection use their own codes for missing data, and these codes are within the range of the COADS true value checks. All of these reports were excluded from the consideration. Then all reports that include at least six first parameters were extracted from COADS CMR. The second most significant parameters were not used due to their low quality and infrequent appearance in the reports.

Visible presence of reports that include wave observations appears in COADS in the second part of 1963. Thus, we restricted the actual period to 30 years (19641993) to have a relatively homogeneous dataset. Figure 1 shows the percentage of reports that selected from the total number of COADS CMR and LMR for the period 1964-93. In most Marsden squares the contribution of 


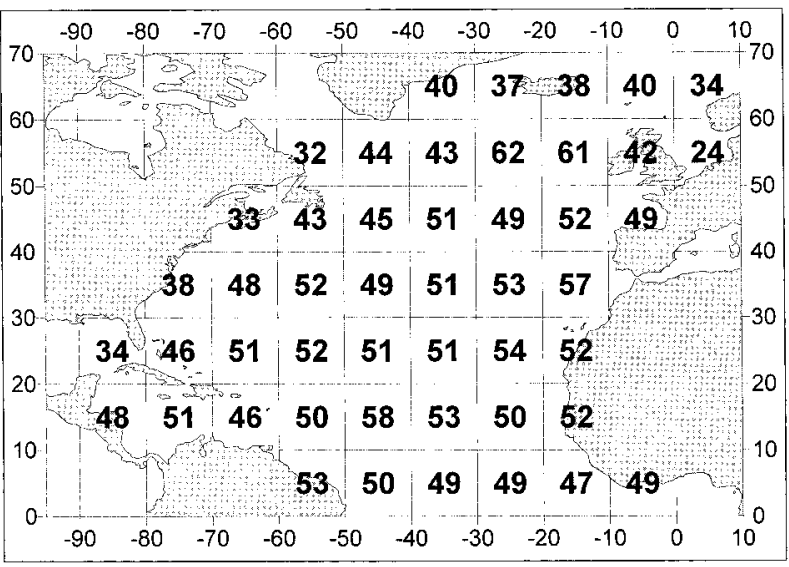

FIG. 1. Percentage of reports with wave observations in the total number of the COADS reports for 1963-93.

reports with wave observations exceeds $40 \%$. Lower relative contributions appear in areas along the North American east coast, in the North Sea, and in high latitudes. However, in many of these regions, the total number of COADS reports is very high, so even $20 \%$ of reports give the absolute number, which is considerably higher, than those for midocean regions. Figure 2 shows interannual variability of the total number of COADS CMR and LMR without missing basic variables, and those that include wave observations for the whole North Atlantic. A remarkable increase of the number of wave observations appears in 1970. During the 1970s the percentage of reports with wave observations usually closely matches $60 \%$, with the exception of high latitudes where this estimate is slightly lower. There is no indication of pronounced seasonal dependence of the number of wave observations. In the Tropics and subtropics their frequency is slightly higher in spring, and in high latitudes there is a weak maximum in autumn. In general, we can point out that the COADS collection provides the first look at a sufficient number of reports with wave observations. Many areas in the Pacific, Indian, and the South Atlantic Ocean covered by climatologies of individual variables and fluxes (Oberhuber 1988; da Silva et al. 1994; Hasse et al. 1996) have an even smaller number of reports in comparison with those that include wave variables in the North Atlantic. Data collection in the COADS Release 1a for the 1980 s and early 1990s is still poor in places in comparison with Release 1 for the earlier decades. Although there is a general tendency of increase of the relative contribution of the reports with wave estimates in the 1980s and 1990s (Fig. 2), a considerable decrease of the total number of reports in the late 1980s is quite remarkable.

Thus, we evaluated wave parameters for future computations. Evaluation of the other meteorological variables, such as sea surface temperature $\left(T_{w}\right)$, air temperature $\left(T_{a}\right)$, water vapor pressure $\left(e_{z}\right)$, sea level pres-
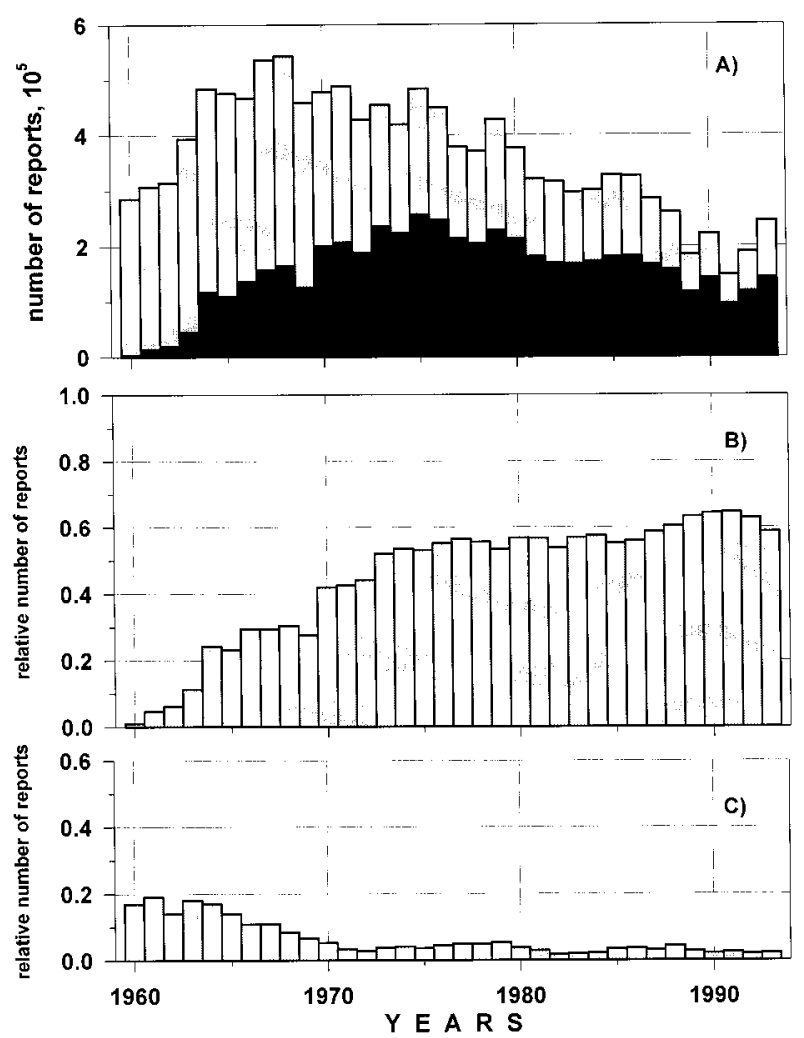

FIG. 2. (a) Total number of reports in COADS that contain basic variables (gray area), and the number of reports that also include wave parameters (black area); (b) relative number (in portion of unity) of reports with wave parameters in the total number of the COADS reports; (c) relative number of reports omitted during the wave age calculations.

sure $\left(P_{a}\right)$, scalar wind speed $(V)$, and direction has been done traditionally. One can find estimates of accuracy of these variables, taken from voluntary observations in Kent et al. (1993) and da Silva et al. (1994). Obtained from individual reports, sampled variables and computed products were averaged into $5^{\circ} \times 5^{\circ}$ boxes over the North Atlantic for each individual month from 1964 to 1993 . We decided not to calculate $2^{\circ} \times 2^{\circ}$ monthly averages as done for the basic parameters in the COADS Monthly Summary Trimmed Groups (MSTG) in order to ensure that our monthly statistics are not influenced by inadequate sampling (Legler 1991) or irregularity in space and time (Weare 1989; Weare and Strub 1981). Monthly means were taken by direct averaging of sampled variables and products, as in COADS MSTG (Slutz et al. 1985). In addition to sea and swell height and period estimates, we computed significant wave height and period to provide relevant background for the intercomparison with in situ measurements.

Significant wave height $H_{s}$, which is originally defined as the mean of the highest one-third of all individual waves in a record, in terms of spectral moments can be expressed as $H_{s}=4 \sqrt{m_{0}}$, where $m_{0}$ is the zeroth moment of the spectrum, which is equal to the sea sur- 
face variance. There are several approaches to estimate significant wave height from the visual observations. Hogben (1988) and many others recommended that $H_{s}$ be computed as

$$
H_{s}=\left(h_{w}^{2}+h_{s}^{2}\right)^{1 / 2} .
$$

This formula has been used in Ocean Wave Statistics (Hogben and Lumb 1967), Global Wave Statistics (Hogben et al. 1986), and in the wind and wave summaries of Paskausky et al. (1984). MCA used the higher of sea or swell heights as an estimate of $H_{s}$. This approach was justified by comparison of visual observations with selected buoy data (Wilkerson and Earle 1990). Barratt (1991) recommends combining these two approaches by applying Eq. (1) to the cases when sea and swell are within the same $45^{\circ}$ directional sector and by taking the higher of two components in all other cases. The quantitative estimate of the appropriate directional sector in different naval and engineering documents varies from $30^{\circ}$ to $60^{\circ}$. We have computed five different estimates of $H_{s}$ by using Eq. (1), taking the higher of sea or swell $\left(H_{h}\right)$ and using the combined method for the directional sectors of $30^{\circ}\left(H_{30}\right), 45^{\circ}$ $\left(H_{45}\right)$, and $60^{\circ}\left(H_{60}\right)$. The resultant wave period $\left(P_{s}\right)$ to be compared with instrumentally measured zero-upcross periods was taken as the period reported with the higher of the two components, as recommended by Wilkerson and Earle (1990), which corresponds to the definition of zero-up-crossing period (Srokosz and Challenor 1987).

Since $30 \%-70 \%$ of available COADS reports were eliminated from the study, as those that do not contain wave information or do not provide a possibility to define clearly required parameters, we first checked whether the results are representative for the North Atlantic climate from the point of view of data coverage. The comparison of the climatological mean scalar wind speed computed from reports with wave observations with those computed from all available COADS CMR and LMR shows that the spatial patterns of both wind fields are very close to each other and to other known climatologies of wind speed. In general, scalar wind computed from reports with wave observations is higher everywhere except for a very limited region in the $\mathrm{Ca}-$ ribbean and Norwegian Sea. Typical differences range from a minimum of $0.1 \mathrm{~m} \mathrm{~s}^{-1}$ to a maximum of $1 \mathrm{~m}$ $\mathrm{s}^{-1}$ and give the mean value of $0.27 \mathrm{~m} \mathrm{~s}^{-1}$. Other variables indicate even better agreement between the whole COADS collection and our dataset. Thus, the selected collection of reports is quite representative to study climatology of wind waves and other variables for the period 1964-93.

\section{Comparison with instrumental measurements}

To evaluate biases in the visual observations, we compared them to instrumental measurements at a number of locations in the North Atlantic. We have used ob- servations from National Data Bouy Center (NDBC) buoys, wave records from OWS L $\left(57^{\circ} \mathrm{N}, 20^{\circ} \mathrm{W}\right)$ and $\mathrm{C}$ $\left(52.5^{\circ} \mathrm{N}, 35.5^{\circ} \mathrm{W}\right)$, and from the Seven Stones Light Vessel (SSLV) $\left(50^{\circ} \mathrm{N}, 6^{\circ} \mathrm{W}\right)$. Monthly summaries and statistics from NDBC buoys were used for 20 locations in the offshore regions of the North American east coast. Time periods vary from several years to nearly 20 years from 1972 to 1993 . Monthly summaries of shipborne wave recorder data are available for the period 197588 at OWS L and for 1968-86 at SSLV (Bacon and Carter 1989, 1991). OWS C provides 11 monthly series of observations during the period 1979-84, taken with wave recorder GM-16 (Davidan et al. 1985). Wilkerson and Earle (1990), studying differences between buoy and VOS data, selected VOS observations taken simultaneously with those measured by buoy instruments within $25-100 \mathrm{~km}$. For the comparison of monthly means and statistics we have computed spatial correlation functions around the points of instrumental measurements (either buoys or OWS) and then selected all VOS observations for individual months within the correlation ellipse of 0.8 . The linear dimensions of these ellipses vary from 60 to $200 \mathrm{~km}$ along the major axis of the spatial correlation function and from 20 to 120 $\mathrm{km}$ across the major axis of the spatial correlation function. The largest ellipses are obtained for OWS L and $\mathrm{C}$, and the smallest for the buoys in the subtropics and the Gulf of Mexico region. Table 1 summarizes results of the comparison for all buoys, OWS, and the SSLV.

The best estimates of significant wave height appear to be either $H_{h}$ or $H_{30}$, which give the mean "buoy minus VOS" differences of -0.03 and $-0.07 \mathrm{~m}$ respectively. Significant wave height defined by (1) overestimates instrumental values everywhere by several tens of centimeters with the mean deviation of $-0.27 \mathrm{~m}$. This is in agreement with Wilkerson and Earle (1990), who found $H_{h}$ to be a better estimate than $\left(h_{w}^{2}+h_{s}^{2}\right)^{1 / 2}$, although they did not consider combined estimates. Estimate $H_{30}$ fits better to the instrumental data in regions with higher directional steadiness of sea and swell. In the locations of OWS $\mathrm{C}$ and $\mathrm{L}$, even the estimated $H_{45}$ gives better agreement with instrumental measurements than $H_{h}$. Alternatively, in the west subtropical Atlantic where wave directional steadiness is low, estimate $H_{h}$ fits the measurements better. Figure 3 shows scatterplots for selected locations and demonstrates rather good agreement between visual and instrumental data if an appropriate estimate of $H_{s}$ is taken. Thus, for SSLV estimated $H_{s}$ indicates a visible bias in comparison with the $H_{h}$ estimate (Figs. 3c,d). Wilkerson and Earle (1990), considering differences between individual visual estimates and simultaneous buoy measurements, obtained large standard deviations (std dev) of the differences (from 1 to $3 \mathrm{~m}$ ). We have computed std dev of monthly differences (Table 1), which are reasonably smaller and vary primarily from 0.1 to $0.5 \mathrm{~m}$. The largest std dev are obtained at OWS L in comparison with NDBC buoys (Figs. 3a,b). Comparison of wave height distributions 
TABLE 1. Means (top numbers) and std dev (bottom numbers) of "bouy minus VOS" differences for different wave parameters. Bold numbers indicate the best agreement between certain visual estimates of significant wave height and instrumental data.

\begin{tabular}{|c|c|c|c|c|c|c|c|c|c|}
\hline Point & $\begin{array}{l}\text { Lat, long } \\
\left({ }^{\circ} \mathrm{N},{ }^{\circ} \mathrm{W}\right)\end{array}$ & $\begin{array}{c}\text { Period } \\
\text { mo.yr }\end{array}$ & $H_{s}$ & $H_{h}$ & $H_{30}$ & $H_{45}$ & $H_{60}$ & $P_{s}$ & $\begin{array}{l}\text { Number } \\
\text { of months }\end{array}$ \\
\hline 41001 & $34.7,72.7$ & $\begin{array}{l}06.76 \\
12.93\end{array}$ & $\begin{array}{r}-0.29 \\
0.24\end{array}$ & $\begin{array}{l}0.11 \\
0.30\end{array}$ & $\begin{array}{l}0.03 \\
0.27\end{array}$ & $\begin{array}{r}-0.06 \\
0.23\end{array}$ & $\begin{array}{r}-0.10 \\
0.29\end{array}$ & $\begin{array}{l}0.44 \\
0.49\end{array}$ & 171 \\
\hline 41002 & $32.3,75.2$ & $\begin{array}{l}12.73 \\
12.93\end{array}$ & $\begin{array}{r}-0.19 \\
0.11\end{array}$ & $\begin{array}{l}0.13 \\
0.14\end{array}$ & $\begin{array}{r}-0.04 \\
0.14\end{array}$ & $\begin{array}{r}-0.09 \\
0.13\end{array}$ & $\begin{array}{r}-0.16 \\
0.17\end{array}$ & $\begin{array}{l}0.33 \\
0.56\end{array}$ & 174 \\
\hline 41003 & $30.3,80.4$ & $\begin{array}{l}07.77 \\
01.82\end{array}$ & $\begin{array}{r}-0.14 \\
0.74\end{array}$ & $\begin{array}{l}0.08 \\
0.47\end{array}$ & $\begin{array}{r}-0.04 \\
0.51\end{array}$ & $\begin{array}{r}-0.09 \\
0.42\end{array}$ & $\begin{array}{r}-0.12 \\
0.49\end{array}$ & $\begin{array}{l}0.19 \\
0.36\end{array}$ & 26 \\
\hline 41004 & $32.5,79.1$ & $\begin{array}{l}06.78 \\
12.93\end{array}$ & $\begin{array}{r}-0.43 \\
0.37\end{array}$ & $\begin{array}{r}-0.26 \\
0.29\end{array}$ & $\begin{array}{r}-0.31 \\
0.29\end{array}$ & $\begin{array}{r}-0.36 \\
0.30\end{array}$ & $\begin{array}{r}-0.39 \\
0.34\end{array}$ & $\begin{array}{l}0.22 \\
0.40\end{array}$ & 37 \\
\hline 41005 & $31.7,79.7$ & $\begin{array}{l}03.79 \\
01.82\end{array}$ & $\begin{array}{r}-0.17 \\
0.24\end{array}$ & $\begin{array}{r}-0.06 \\
0.29\end{array}$ & $\begin{array}{r}-0.08 \\
0.25\end{array}$ & $\begin{array}{r}-0.14 \\
0.22\end{array}$ & $\begin{array}{r}-0.16 \\
0.25\end{array}$ & $\begin{array}{r}-0.03 \\
0.39\end{array}$ & 13 \\
\hline 41006 & $29.3,77.4$ & $\begin{array}{l}05.82 \\
12.93\end{array}$ & $\begin{array}{r}-0.41 \\
0.54\end{array}$ & $\begin{array}{r}-0.19 \\
0.48\end{array}$ & $\begin{array}{r}-0.22 \\
0.43\end{array}$ & $\begin{array}{r}-0.29 \\
0.41\end{array}$ & $\begin{array}{r}-0.36 \\
0.40\end{array}$ & $\begin{array}{l}0.37 \\
0.51\end{array}$ & 118 \\
\hline 41010 & $28.9,78.5$ & $\begin{array}{l}11.88 \\
12.93\end{array}$ & $\begin{array}{r}-0.46 \\
0.71\end{array}$ & $\begin{array}{r}-0.24 \\
0.73\end{array}$ & $\begin{array}{r}-0.31 \\
0.68\end{array}$ & $\begin{array}{r}-0.33 \\
0.59\end{array}$ & $\begin{array}{r}-0.42 \\
0.60\end{array}$ & $\begin{array}{l}0.49 \\
0.38\end{array}$ & 71 \\
\hline 41016 & $24.6,76.5$ & $\begin{array}{l}05.92 \\
12.93\end{array}$ & $\begin{array}{r}-0.92 \\
0.63\end{array}$ & $\begin{array}{r}-0.74 \\
0.52\end{array}$ & $\begin{array}{r}-0.79 \\
0.60\end{array}$ & $\begin{array}{r}-0.81 \\
0.58\end{array}$ & $\begin{array}{r}-0.84 \\
0.56\end{array}$ & $\begin{array}{r}-0.34 \\
0.49\end{array}$ & 18 \\
\hline 42001 & $25.9,89.7$ & $\begin{array}{l}08.75 \\
12.93\end{array}$ & $\begin{array}{r}-0.22 \\
0.14\end{array}$ & $\begin{array}{l}0.14 \\
0.19\end{array}$ & $\begin{array}{l}0.03 \\
0.13\end{array}$ & $\begin{array}{r}-0.07 \\
0.16\end{array}$ & $\begin{array}{r}-0.13 \\
0.16\end{array}$ & $\begin{array}{l}0.36 \\
0.41\end{array}$ & 192 \\
\hline 42003 & $25.9,85.9$ & $\begin{array}{l}11.76 \\
12.93\end{array}$ & $\begin{array}{r}-0.19 \\
0.16\end{array}$ & $\begin{array}{l}0.19 \\
0.23\end{array}$ & $\begin{array}{l}0.08 \\
0.14\end{array}$ & $\begin{array}{r}-0.13 \\
0.17\end{array}$ & $\begin{array}{r}-0.14 \\
0.15\end{array}$ & $\begin{array}{l}0.40 \\
0.46\end{array}$ & 176 \\
\hline 42025 & $24.9,80.4$ & $\begin{array}{l}09.91 \\
12.93\end{array}$ & $\begin{array}{r}-0.17 \\
0.54\end{array}$ & $\begin{array}{r}-0.08 \\
0.57\end{array}$ & $\begin{array}{r}-0.10 \\
0.49\end{array}$ & $\begin{array}{r}-0.15 \\
0.51\end{array}$ & $\begin{array}{r}-0.15 \\
0.53\end{array}$ & $\begin{array}{r}-0.21 \\
0.64\end{array}$ & 25 \\
\hline 44001 & $38.4,73.6$ & $\begin{array}{l}10.75 \\
04.91\end{array}$ & $\begin{array}{r}-0.26 \\
0.49\end{array}$ & $\begin{array}{r}-0.01 \\
0.49\end{array}$ & $\begin{array}{r}-0.05 \\
0.42\end{array}$ & $\begin{array}{r}-0.11 \\
0.44\end{array}$ & $\begin{array}{r}-0.14 \\
0.46\end{array}$ & $\begin{array}{l}0.31 \\
0.63\end{array}$ & 28 \\
\hline 44003 & $40.8,68.5$ & $\begin{array}{l}03.77 \\
03.84\end{array}$ & $\begin{array}{r}-0.33 \\
0.51\end{array}$ & $\begin{array}{l}0.21 \\
0.49\end{array}$ & $\begin{array}{r}-0.04 \\
0.43\end{array}$ & $\begin{array}{r}-0.19 \\
0.45\end{array}$ & $\begin{array}{r}-0.26 \\
0.51\end{array}$ & $\begin{array}{l}0.10 \\
0.38\end{array}$ & 45 \\
\hline 44004 & $38.5,70.7$ & $\begin{array}{l}09.77 \\
12.93\end{array}$ & $\begin{array}{r}-0.36 \\
0.31\end{array}$ & $\begin{array}{r}-0.11 \\
0.23\end{array}$ & $\begin{array}{r}-0.07 \\
\mathbf{0 . 2 0}\end{array}$ & $\begin{array}{r}-0.16 \\
0.26\end{array}$ & $\begin{array}{r}-0.18 \\
0.28\end{array}$ & $\begin{array}{l}0.32 \\
0.69\end{array}$ & 161 \\
\hline 44005 & $42.6,68.6$ & $\begin{array}{l}12.78 \\
12.93\end{array}$ & $\begin{array}{r}-0.28 \\
0.44\end{array}$ & $\begin{array}{l}0.09 \\
0.18\end{array}$ & $\begin{array}{l}0.02 \\
0.21\end{array}$ & $\begin{array}{r}-0.08 \\
0.15\end{array}$ & $\begin{array}{r}-0.16 \\
0.19\end{array}$ & $\begin{array}{l}0.11 \\
0.32\end{array}$ & 167 \\
\hline 44008 & $40.5,69.4$ & $\begin{array}{l}08.82 \\
12.93\end{array}$ & $\begin{array}{r}-0.26 \\
0.22\end{array}$ & $\begin{array}{l}0.08 \\
0.29\end{array}$ & $\begin{array}{r}-0.05 \\
0.18\end{array}$ & $\begin{array}{r}-0.09 \\
0.16\end{array}$ & $\begin{array}{r}-0.20 \\
0.20\end{array}$ & $\begin{array}{l}0.43 \\
0.21\end{array}$ & 111 \\
\hline 44011 & $41.1,66.6$ & $\begin{array}{l}05.84 \\
10.93\end{array}$ & $\begin{array}{r}-0.32 \\
0.11\end{array}$ & $\begin{array}{r}-0.11 \\
0.14\end{array}$ & $\begin{array}{r}-0.14 \\
0.14\end{array}$ & $\begin{array}{r}-0.25 \\
0.13\end{array}$ & $\begin{array}{r}-0.29 \\
0.13\end{array}$ & $\begin{array}{l}0.13 \\
0.28\end{array}$ & 86 \\
\hline 44014 & $36.6,74.8$ & $\begin{array}{l}10.90 \\
12.93\end{array}$ & $\begin{array}{r}-0.36 \\
0.64\end{array}$ & $\begin{array}{l}0.16 \\
0.59\end{array}$ & $\begin{array}{l}0.01 \\
0.56\end{array}$ & $\begin{array}{r}-0.04 \\
0.61\end{array}$ & $\begin{array}{r}-0.21 \\
0.64\end{array}$ & $\begin{array}{l}0.51 \\
0.45\end{array}$ & 39 \\
\hline EB10 & $27.5,88.0$ & $\begin{array}{l}10.72 \\
01.76\end{array}$ & $\begin{array}{r}-0.11 \\
0.17\end{array}$ & $\begin{array}{l}0.24 \\
0.19\end{array}$ & $\begin{array}{l}0.10 \\
0.24\end{array}$ & $\begin{array}{l}0.01 \\
0.16\end{array}$ & $\begin{array}{r}-0.05 \\
0.17\end{array}$ & $\begin{array}{r}-0.23 \\
0.06\end{array}$ & 7 \\
\hline LNEL1 & $28.2,89.1$ & $\begin{array}{l}06.91 \\
06.92\end{array}$ & $\begin{array}{r}-0.22 \\
0.26\end{array}$ & $\begin{array}{l}0.07 \\
0.21\end{array}$ & $\begin{array}{l}0.01 \\
0.22\end{array}$ & $\begin{array}{r}-0.09 \\
0.24\end{array}$ & $\begin{array}{r}-0.14 \\
0.22\end{array}$ & $\begin{array}{l}0.03 \\
0.16\end{array}$ & 4 \\
\hline SSLV & $50.0,06.0$ & $\begin{array}{l}01.68 \\
12.86\end{array}$ & $\begin{array}{r}-0.34 \\
0.27\end{array}$ & $\begin{array}{r}-0.10 \\
0.18\end{array}$ & $\begin{array}{r}-0.13 \\
0.24\end{array}$ & $\begin{array}{r}-0.23 \\
0.27\end{array}$ & $\begin{array}{r}-0.26 \\
0.27\end{array}$ & $\begin{array}{l}0.69 \\
0.44\end{array}$ & 190 \\
\hline OWS L & $57.0,20.0$ & $\begin{array}{l}07.75 \\
12.88\end{array}$ & $\begin{array}{r}-0.23 \\
0.35\end{array}$ & $\begin{array}{r}-0.10 \\
0.36\end{array}$ & $\begin{array}{r}-0.06 \\
0.39\end{array}$ & $\begin{array}{r}-0.09 \\
0.35\end{array}$ & $\begin{array}{r}-0.19 \\
0.32\end{array}$ & $\begin{array}{l}0.50 \\
0.36\end{array}$ & 156 \\
\hline OWS C & $52.5,35.5$ & $\begin{array}{l}02.79 \\
09.84\end{array}$ & $\begin{array}{r}-0.16 \\
0.36\end{array}$ & $\begin{array}{l}0.19 \\
0.39\end{array}$ & $\begin{array}{l}0.07 \\
0.28\end{array}$ & $\begin{array}{r}-0.03 \\
\mathbf{0 . 2 9}\end{array}$ & $\begin{array}{r}-0.11 \\
0.31\end{array}$ & $\begin{array}{l}0.22 \\
0.43\end{array}$ & 11 \\
\hline
\end{tabular}

(not shown here) also indicates good agreement between the visual and measured data. Note here that the comprehensive comparisons of measured and visually estimated wave heights, undertaken by Hogben et al. (1983) and Dacunha et al. (1984) for a number of primarily midlatitudinal areas, showed good agreement for both climatological means and statistical properties.

If we consider wave periods (Table 1), there will be a systematic underestimation of visual estimates in comparison with instrumental measurements by several tenths of a second with a mean departure of $0.26 \mathrm{~s}$ and std dev of $0.1-0.6 \mathrm{~s}$. In general, sites exposed to high levels of swell (OWS C, L, and SSLV) indicate slightly larger "buoy minus VOS" biases in periods than NDBC buoys primarily sheltered from swell. Underestimation of visual periods by several tenths of a second is a known problem of the VOS observations. Particularly Wilkerson and Earle (1990) reported about $0.2 \mathrm{~s}$ buoy minus VOS differences. Figure 4 shows the occurrence histograms for SSLV and NDBC buoy 44005 computed 

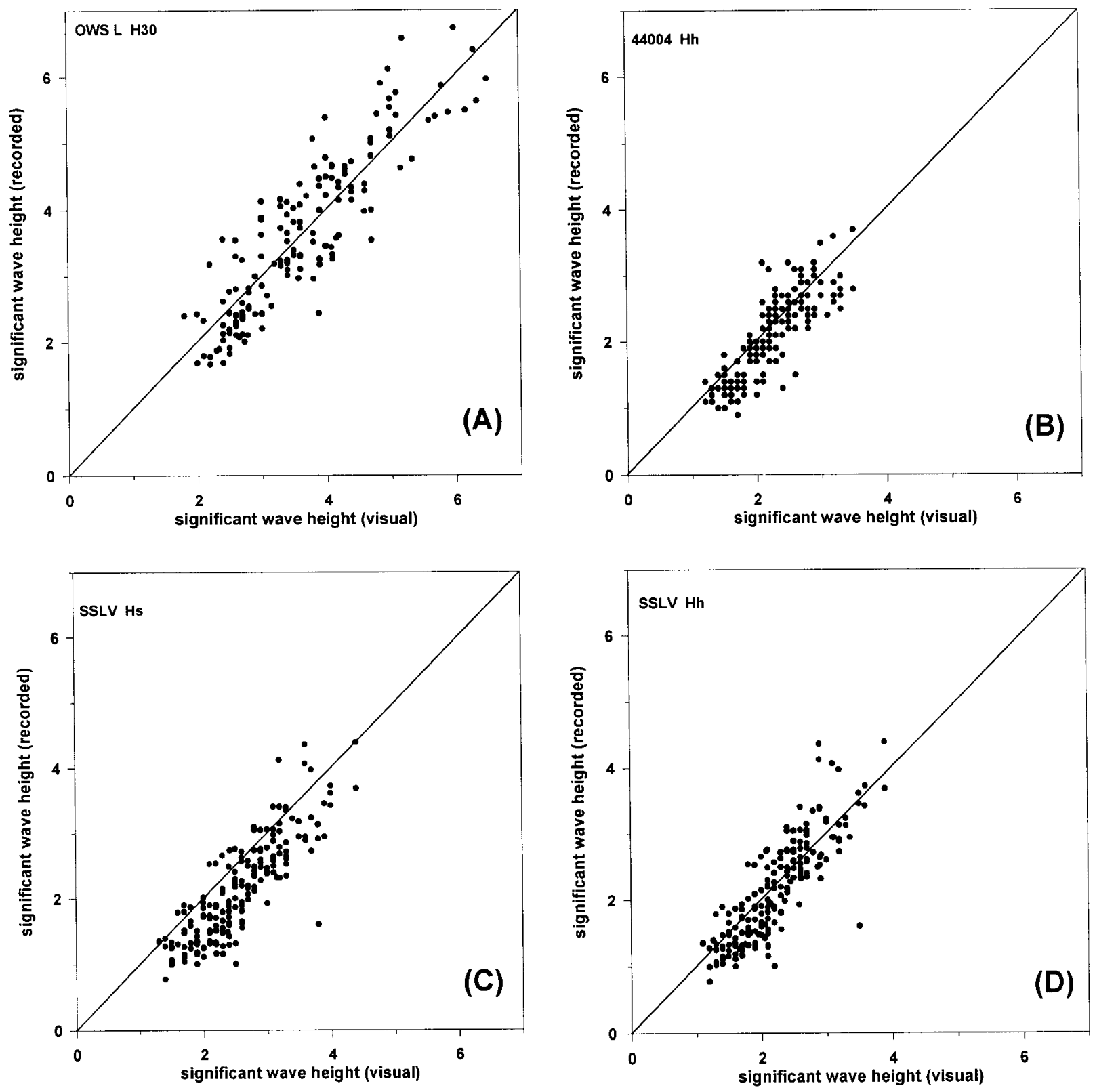

FIG. 3. Scatterplots of the visually estimated and measured significant wave height at OWS, estimate $H_{30}$ (a); NDBC buoy 44004, estimate $H_{h}(\mathrm{~b})$; and SSLV, estimates $\left(h_{w}^{2}+h_{s}^{2}\right)^{1 / 2}(\mathrm{c})$ and $H_{h}(\mathrm{~d})$.

from instrumental observations and VOS. Probability distributions of instrumental data were taken from NDBC buoy CD-ROMs and from Bacon and Carter (1989). VOS data indicate larger variance and, at least in the northeast Atlantic, demonstrate clearly the shift of the maximum of the the VOS probability distribution to shorter periods in comparison with instrumental data. This shift is not as large as those obtained by Dacunha et al. (1984) and Hogben (1988), particularly for Cobb Seamount in the North Pacific and for the South Ocean. Dacunha et al. suggested a period correction using a joint lognormal distribution of wave height with wave period. Their formulas $\mu\left(\ln P_{s}\right)=1.818+0.297 \mu$ $\left(\ln H_{s}\right)$ for high swells and $\mu\left(\ln P_{s}\right)=1.515+0.266 \mu$ $\left(\ln H_{s}\right)$ for limited fetches make it possible to compute mean climatological values of $\ln P_{s}$ from mean values of $\ln H_{s}$ and then to determine all parameters of the joint probability distribution of wave height and period avoiding any use of visually observed periods. However, these formulas were calibrated only in eastern ocean midlatitudes and give large overestimation of wave periods in the other regions. Moreover, this approach does not provide for the correction of individual observations. We have developed correction formulas for sea 

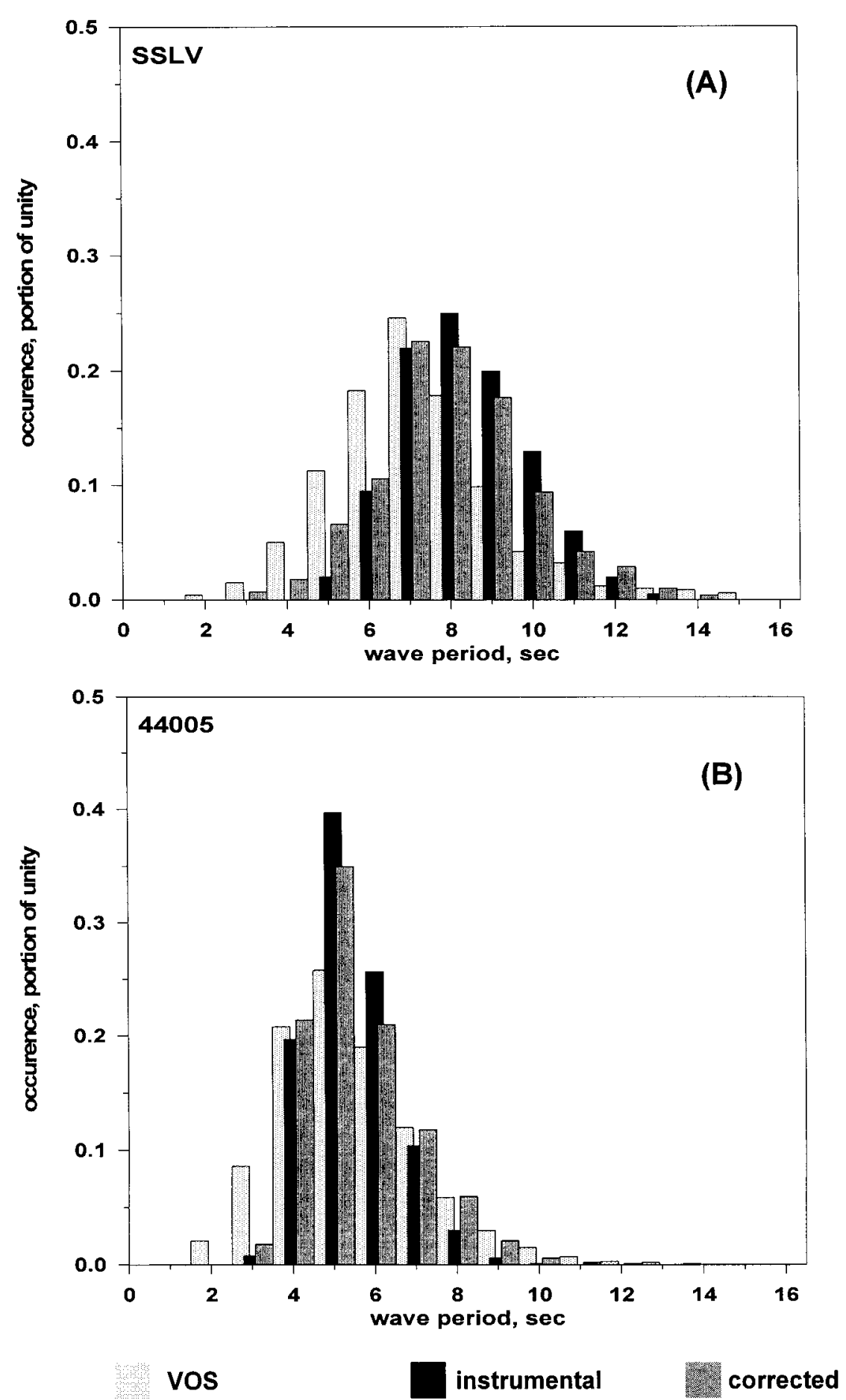

FIG. 4. Occurrence histograms for the originally estimated (light gray), measured (black), and corrected (deep gray) resultant wave period at SSLV (A) and NDBC buoy 44005 (B).

and swell periods by fitting joint distributions of wave height and period for every calendar month in 17 locations of the North Atlantic, that included 14 NDBC buoys, OWS C and L, and the SSLV. Empirical formulas are the following:

$$
\begin{aligned}
& p_{w}^{\prime}=A_{w} \ln \left(p_{w}+B_{w}\right)+C_{w} \ln \left(h_{w}\right), \\
& p_{s}^{\prime}=A_{s} \ln \left(p_{s}+B_{s}\right)+C_{s} \ln \left(h_{w}\right),
\end{aligned}
$$

where $p_{w}^{\prime}$ and $p_{s}^{\prime}$ are the corrected sea and swell periods, used then for the computation of $P_{s}$. Empirical coeffi- 
TABLE 2. Empirical coefficients of Eq. (2) for different conditions.

\begin{tabular}{ccccccc}
\hline \hline Cases & $A_{w}$ & $B_{w}$ & $C_{w}$ & $A_{s}$ & $B_{s}$ & $C_{s}$ \\
\hline
\end{tabular}

Sea and swell within $45^{\circ}$ sector

$\begin{array}{lllllll}\text { Sea higher than swell } & 3.421 & 1.976 & 0.574 & 4.658 & 0.624 & -0.822\end{array}$

Swell higher than sea $\quad 0.498 \quad-0.893$

Sea and swell without $45^{\circ}$ sector

$\begin{array}{lllllll}\text { Sea higher than swell } & 2.641 & 1.569 & 0.516 & 3.186 & 1.154 & -0.933\end{array}$

Swell higher than sea

0.429 $-0.989$

cients $A_{w}, B_{w}, C_{w}, A_{s}, B_{s}$, and $C_{s}$ were determined by the comparison of the distributions $\left(P_{s} \mid H_{s}\right)$ for instrumental and VOS data and were selected for the best fits of distributions to each other for all seasons and locations. Table 2 displays the values of the coefficients that should be taken for the cases when sea and swell are within the same $45^{\circ}$ directional sector, and without this sector, as well as for the cases when swell is higher than sea, and vice versa. In this way we have accounted for the differences between cases with high and low swells
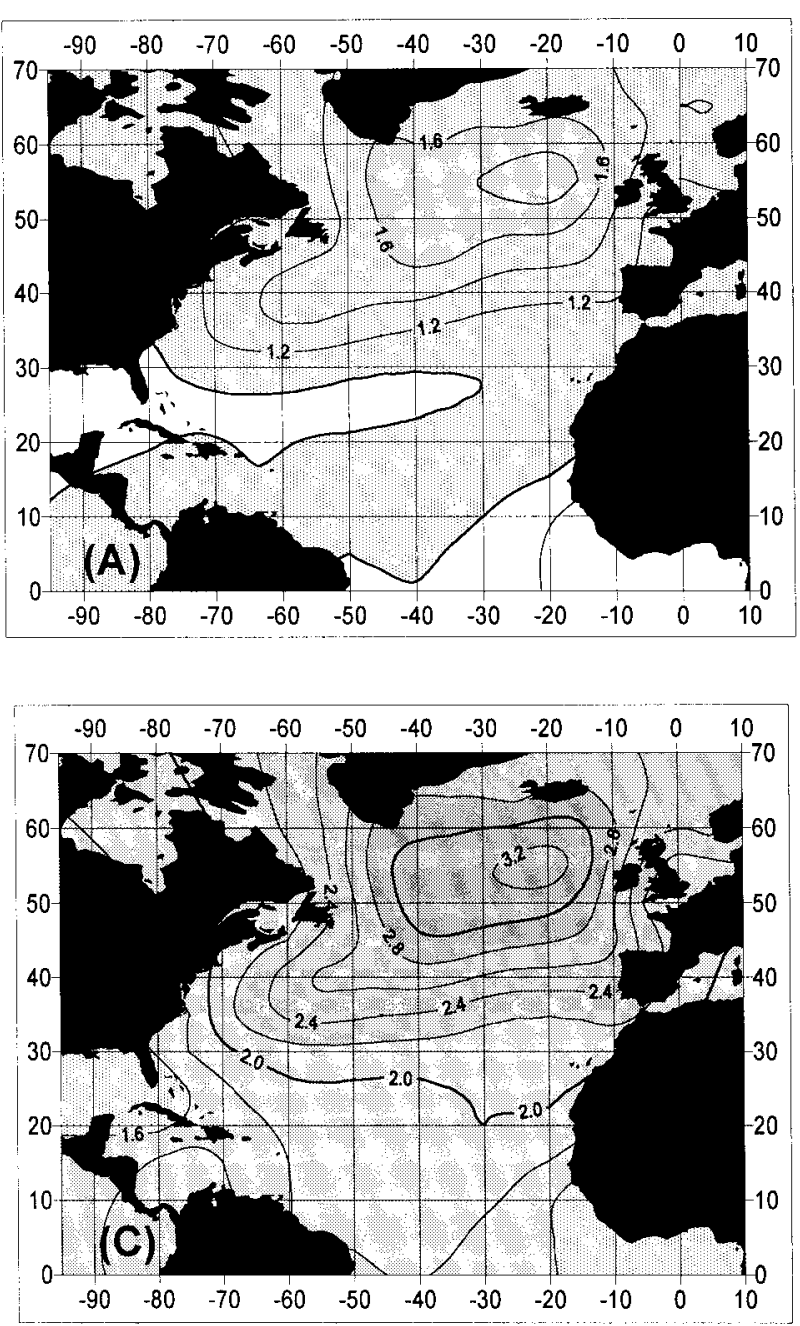

that assume different corrections (Dacunha et al. 1984). Resultant periods computed from sea and swell periods corrected using Eq. (2) with the coefficients from Table 2 give an agreement between monthly means of $P_{s}$ computed from VOS and from instrumental data with std dev of the differences of 0.12 . Figure 4 shows the occurrence histograms of the corrected periods, which also indicate similarity of distributions of periods. Dacunha et al.'s (1984) method as well as Ochi's (1978) correction give systematic overestimation of periods in the northeast Atlantic and systematically underestimate periods in the western Atlantic midlatitudes and subtropics.

\section{Climatology of the sea state characteristics}

Figure 5 shows climatological means of visually estimated sea and swell heights. The highest annual mean sea height of $1.9 \mathrm{~m}$ is observed in the northeast Atlantic at $20^{\circ} \mathrm{W}$, and the smallest heights appear in the equatorial
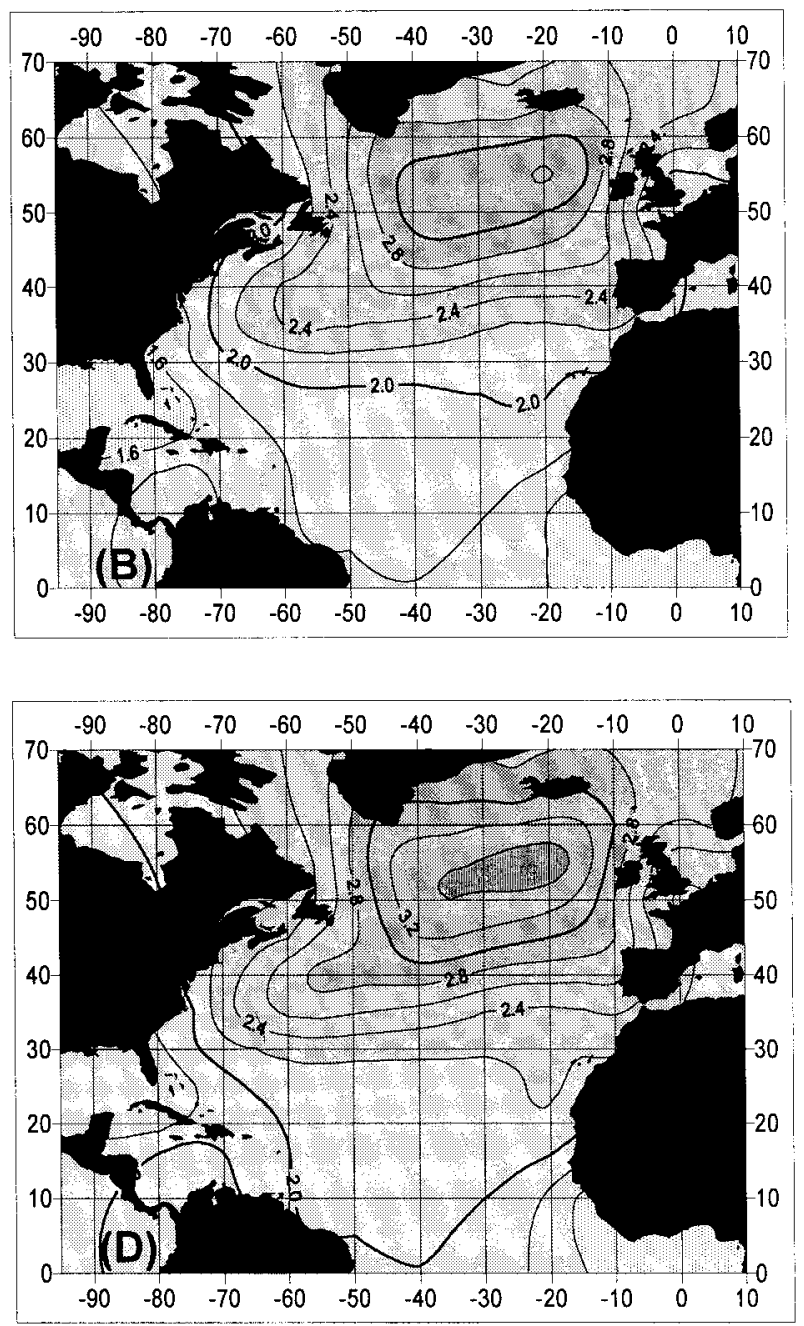

FIG. 5. Annual mean sea (a) and swell (b) height and significant wave height estimates $H_{h}$ (c) and $H_{30}$ (d). Units are meters. 
area where they vary from $0.7 \mathrm{~m}$ to $0.9 \mathrm{~m}$. A local minimum in the subtropics indicates heights from 0.8 $\mathrm{m}$ to $1.0 \mathrm{~m}$. Figure $5 \mathrm{~b}$ indicates the highest annual mean for swell height of $3.0 \mathrm{~m}$ in the northeast Atlantic, and the lowest annual mean swell of $1.5 \mathrm{~m}$ in the equatorial area. Since the propagation of swell is from the area of generation to other remote regions, one should not expect the collocation of sea and swell height maxima and minima. Although there is a general similarity of the spatial distribution of swell height with wave height, the subtropical minimum and the tropical maximum in swell height are not as visible as for the sea. In the North Atlantic midlatitudes the shift between swell and sea maxima is not so pronounced due to the coupling of different swell systems for the midlatitudinal storm track area. In this case the effect is more pronounced in the period fields rather than in the height field (Fig. 8). Annual charts of the estimates of significant wave height are shown in Fig. 5c for estimated $H_{h}$ and in Fig. $5 \mathrm{~d}$ for estimated $H_{30}$. The latter reasonably gives $0.1-$ $0.25 \mathrm{~m}$ higher values. The highest significant wave height is observed in the northeast Atlantic midlatitudes where it is higher than $3.2 \mathrm{~m}$.
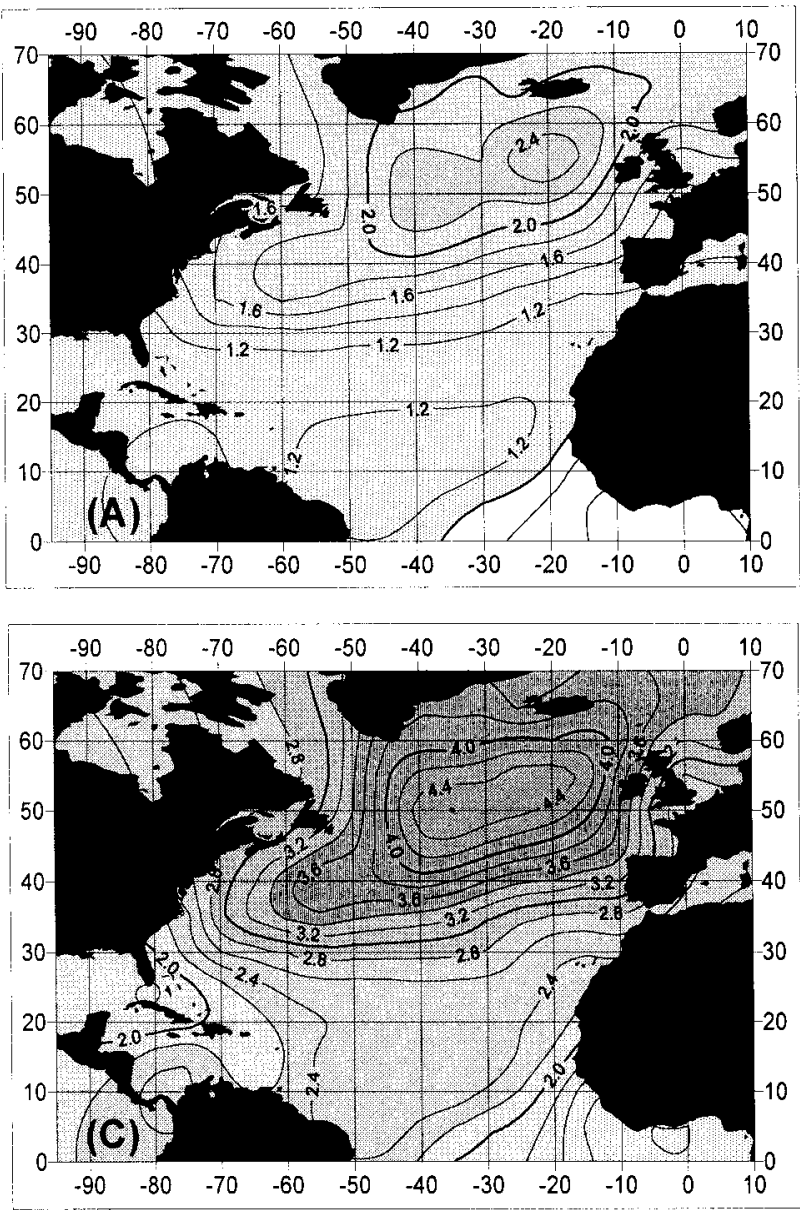

Figure 6 displays monthly maps of the sea height and significant wave height $\left(H_{30}\right)$ for winter and summer, and Fig. 7 shows the seasonal cycle of zonal averages for sea, swell, and significant wave heights. The highest waves are observed in winter in the northeast Atlantic, where they range from 2.2 to $2.5 \mathrm{~m}$. In summer the northeast Atlantic maximum gives a $1.3-\mathrm{m}$ wave height. A pronounced local maximum of wave height appears in the Gulf Stream area at $40^{\circ} \mathrm{N}$ during winter and spring and is characterized by heights of $1.8 \mathrm{~m}$ and $1.5 \mathrm{~m}$ respectively. Annual variation of the subtropical minimum is from $0.7 \mathrm{~m}$ in summer to $1.1 \mathrm{~m}$ during winter. Seasonal march is pronounced for all latitudes north of $10^{\circ} \mathrm{N}$. In the Tropics wave heights indicate an additional maximum in May-June and a minimum in SeptemberOctober, which is in agreement with the seasonal cycle of the trade winds. The highest swell heights in January and July are equal to 4.0 and $2.2 \mathrm{~m}$ respectively. The swell height in equatorial regions has a complicated seasonal dependence, characterized by variations within the range $1.4-1.7 \mathrm{~m}$. The highest significant wave height in the northeast Atlantic is $4.6 \mathrm{~m}$ in January and $2.5 \mathrm{~m}$ in July. Annual variation of the tropical maximum is
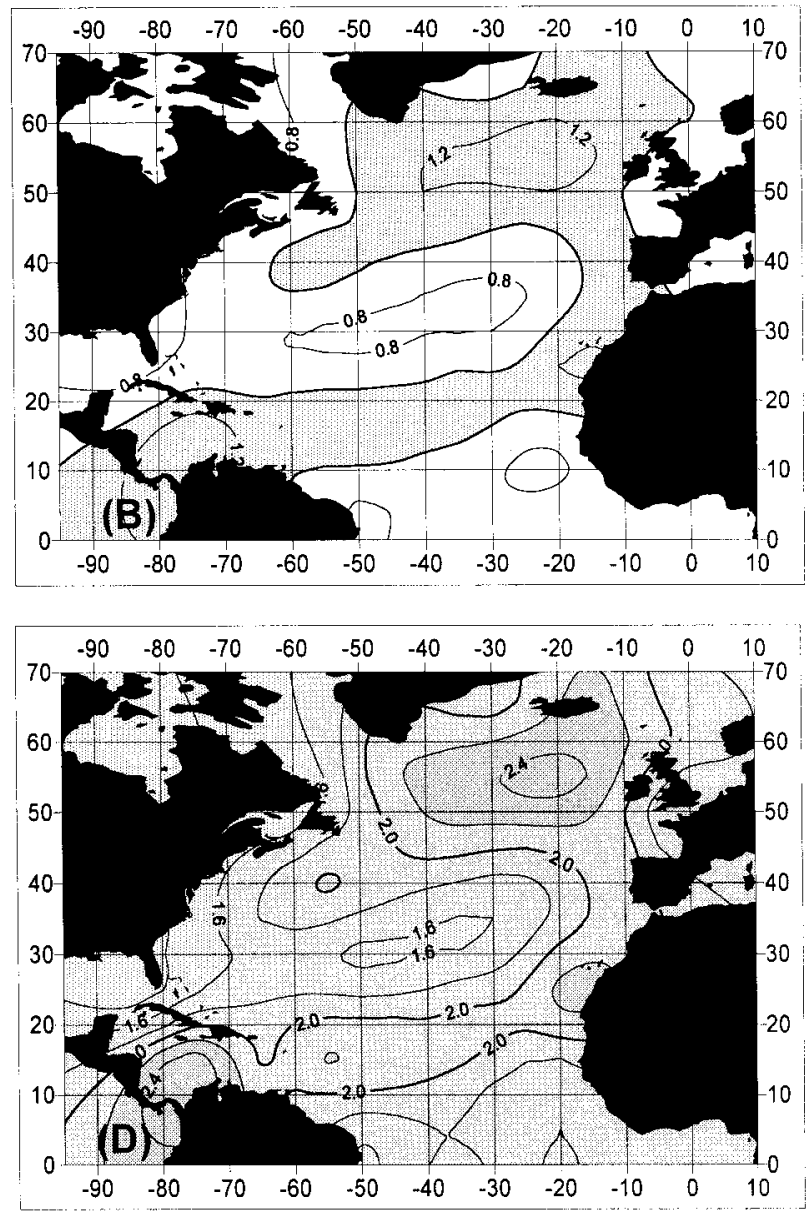

FIG. 6. January (a, c) and July (b, d) monthly mean sea height (a, b) and significant wave height, estimate $H_{30}$ (c, d). Units are meters. 

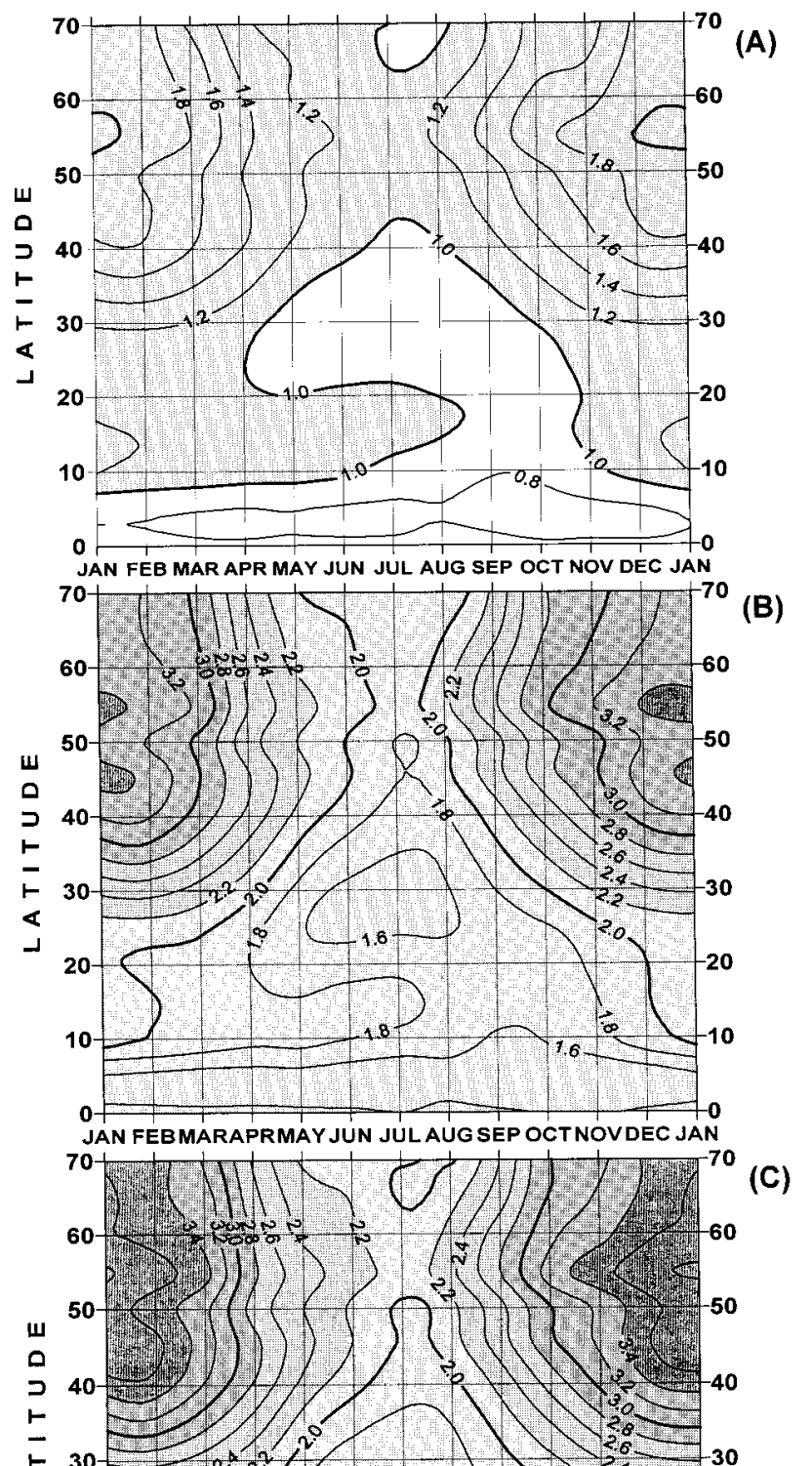

$\leftarrow 30$

$\perp$

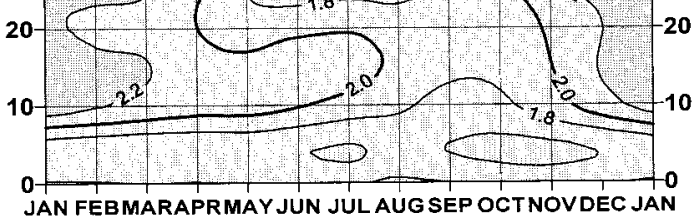

FIG. 7. Annual cycle of zonal averaged sea (a), swell (b), and significant wave height, estimate $H_{30}$ (c). Units are meters.

from $2.2 \mathrm{~m}$ in summer to 2.6 in winter. Seasonal latitudinal diagram for $H_{30}$ (Fig. 7) is similar to those for swell and shows the highest zonal significant height of $3.8 \mathrm{~m}$ in January in midlatitudes, and the lowest heights of 1.6-1.8 $\mathrm{m}$ in the subtropics and equatorial area.

Figure 8 shows annual mean wave period and swell period before and after the correction (2). Corrected periods in general are from 0.1 to $0.5 \mathrm{~s}$ greater than those originally estimated. A sea period absolute maximum of about $5 \mathrm{~s}$ is observed in the northeast Atlantic, subtropical minimum indicates periods of about 3.4-3.5 $\mathrm{s}$, and the smallest periods less than $3.2 \mathrm{~s}$ are located in the equatorial area. Spatial patterns of the swell period are quite different from those for windsea periods. Isolines of swell periods in the North Atlantic midlatitudes and subtropics are primarily directed from north to south and indicate a strong zonal gradient of periods. The longest swells of 8.8-9.0 s are observed in the northeast Atlantic. The minimum is located in the subtropical western Atlantic and indicates values from 6 to $6.6 \mathrm{~s}$. Resultant wave period $P_{s}$ corresponding to the higher of sea or swell heights is shown in Fig. 8e. The largest resultant periods of 7.2-7.5 s are observed in the northeast Atlantic. A subtropical minimum indicates periods from 4.2 to $4.8 \mathrm{~s}$. The absolute minimum of $3.5 \mathrm{~s}$ is located in the equatorial area.

Monthly maps for wind wave and resultant periods are displayed in Fig. 9. Figure 10 displays the diagrams of the seasonal cycle of zonal averaged sea, swell, and resultant periods. The longest sea periods are observed in the northeast Atlantic in winter, when the maximum closely matches $5.5 \mathrm{~s}$. In spring there is another pronounced maximum in the northwest Atlantic, which indicates periods from $4.5-5 \mathrm{~s}$. The subtropical minimum is located at $20^{\circ}-25^{\circ} \mathrm{N}$ in winter and is shifted to $30^{\circ} \mathrm{N}$ in summer, as well as the tropical maximum, which moves from $10^{\circ} \mathrm{N}$ in April to $15^{\circ}-20^{\circ} \mathrm{N}$ in July. This is, in general, coincident with the annual cycle of the trade winds that generate waves in this region. Annual variation of the largest resultant period (Figs. 9c,d) in the northeast Atlantic is from 6.0 to $8.6 \mathrm{~s}$. The subtropical minimum varies from 4.0 to $5.8 \mathrm{~s}$. If we consider the diagram of the seasonal cycle of zonal averaged sea and swell periods (Fig. 10) there will be a remarkable time lag of about 3-4 months between the appearance of a minimum in midlatitudes and the Tropics. For the resultant period this lag is even longer than 5 months. Maximum midlatitudinal zonal values of the sea, swell, and resultant periods are observed in January and equal $4.9,8.8$, and $7.7 \mathrm{~s}$, respectively.

It was interesting to compare our results with the other visual climatologies such as MCA and global wave statistics (Hogben et al. 1986). We have recomputed our results for time periods $1950-78$ and $1950-82$ for the comparison with MCA and Hogben et al. (1986), respectively. MCA indicates general underestimation of significant wave height $\left(H_{h}\right)$ by $8 \%-12 \%$ in the northwest Atlantic midlatitudes and by about $15 \%$ in the northeast Atlantic. Global wave statistics give general underestimation of significant wave height by $10-20 \mathrm{~cm}$ in comparison with our data, but indicate very similar spatial patterns. Wave periods from global wave statistics are in good agreement with our results in the northeast Atlantic midlatitudes and Tropics, but underestimate periods in the west subtropics and midlatitudes. Note here that Hogben et al. (1986) used Dacunha et 

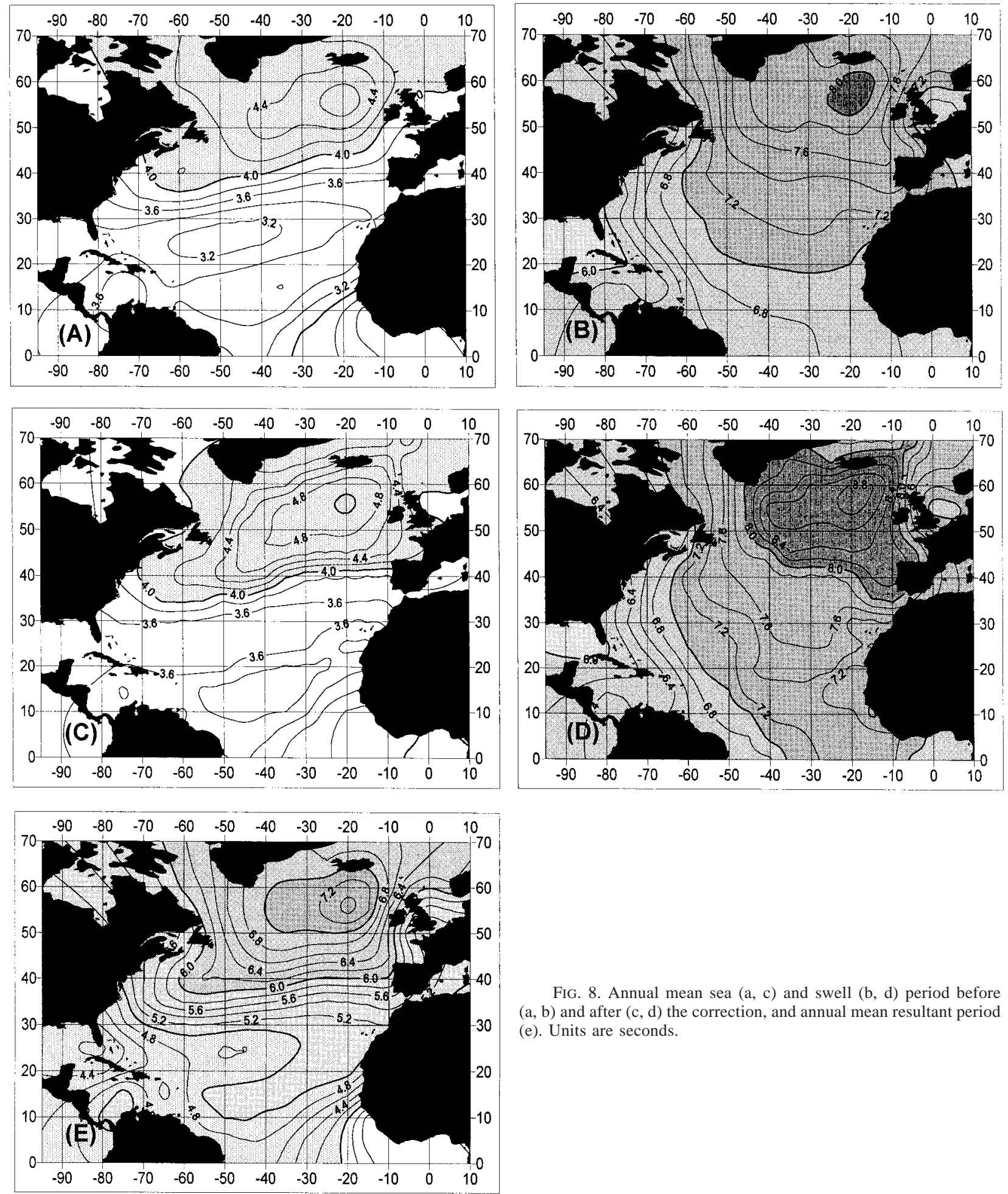

Fig. 8. Annual mean sea $(a, c)$ and swell $(b, d)$ period before $(\mathrm{a}, \mathrm{b})$ and after $(\mathrm{c}, \mathrm{d})$ the correction, and annual mean resultant period (e). Units are seconds.

al.'s (1984) correction of periods, which is based on the comparison with instrumental data primarily in eastern oceanic regions exposed to high swells. Local comparison could be done with Korevaar (1990), who produced
North Sea climatology for most of the time interval (1961-80). He found, that the annual median wave height varies between 1 and $2 \mathrm{~m}$ in the north part of the North Sea and between 0.5 and $1 \mathrm{~m}$ in the south. 

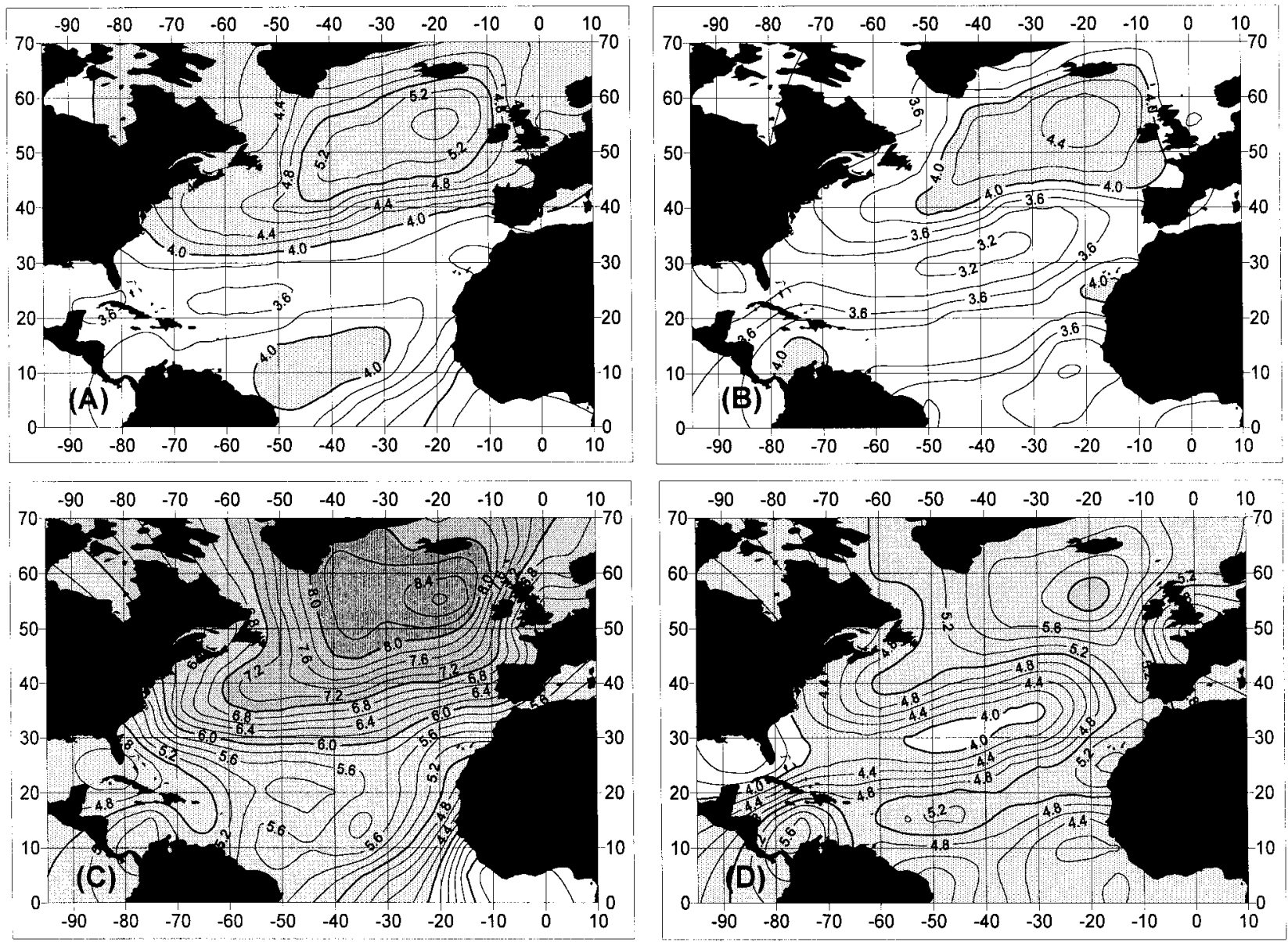

FIG. 9. January (a, c) and July (b, d) monthly mean sea (a, b) and resultant (c, d) periods (s).

We recomputed our results for the North Sea in terms of medians (the median wave height is the height exceeded in $50 \%$ of observations) and obtained for the north part $1.4 \mathrm{~m}$, which agrees well with Korevaar's (1990) estimate.

\section{Evaluation of wave age and sea-state-dependent wind stress from voluntary observing ship data}

To estimate sea-state-dependent wind stress we have to obtain estimates of the wave age. The latter characterizes the stage of wave development and can be defined (Smith 1991) as

$$
a=C_{p} / V_{\mathrm{ef}},
$$

where $C_{p}$ is the deep water wave phase speed at spectral peak and $V_{\text {ef }}$ is the component of wind in the wave direction. In general, if $a<1$, the wave is assumed to be sea, and if $a>1$, the wave is considered swell. An alternative estimate of wave age is given as the ratio between the deep water wave phase speed and the friction velocity $u_{*}$ :

$$
a_{*}=C_{p} / u_{*}
$$

Smith et al. (1992) noted that from a theoretical viewpoint this estimate is more credible (Janssen et al. 1987; Janssen 1989; Perrie and Toulany 1990). At the same time wind speed is a more readily available parameter than $u_{*}$. Estimates of $a_{*}$ vary within the range from 45 (very young sea) to 30-40 (fully developed sea). The deep water wave phase speed was computed from wave period, as

$$
C_{p}=(g / 2 \pi) p_{w} .
$$

Swell does not have (by definition) relations to the local wind, and it is the interaction of the local wind with the windsea that determines the part of the wind stress caused by the waves. Thus, we take the corrected sea period for the evaluation of the wave age and, therefore, of the contribution from sea state to the stress. The effective wind is evaluated from the actual wind vector, as

$$
V_{\text {ef }}=V_{10} \cos \vartheta
$$

where $\vartheta$ is the angle between wave and wind direction and $V_{10}$ is wind speed at a $10-\mathrm{m}$ anemometer reference level. COADS CMR and LMR do not provide infor- 

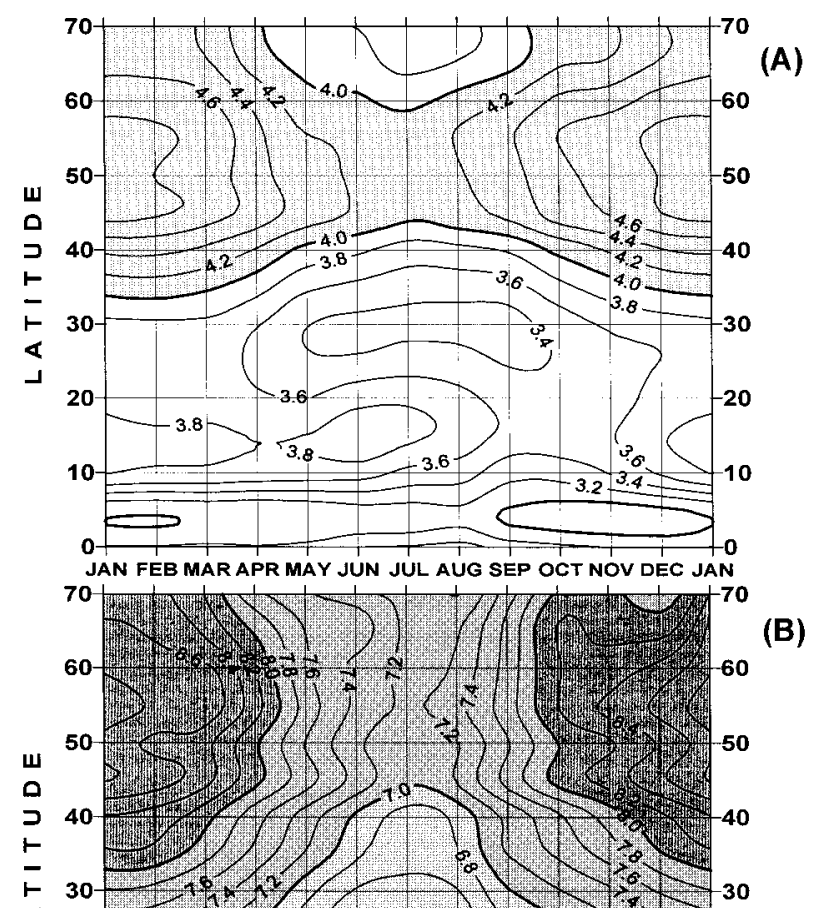

10
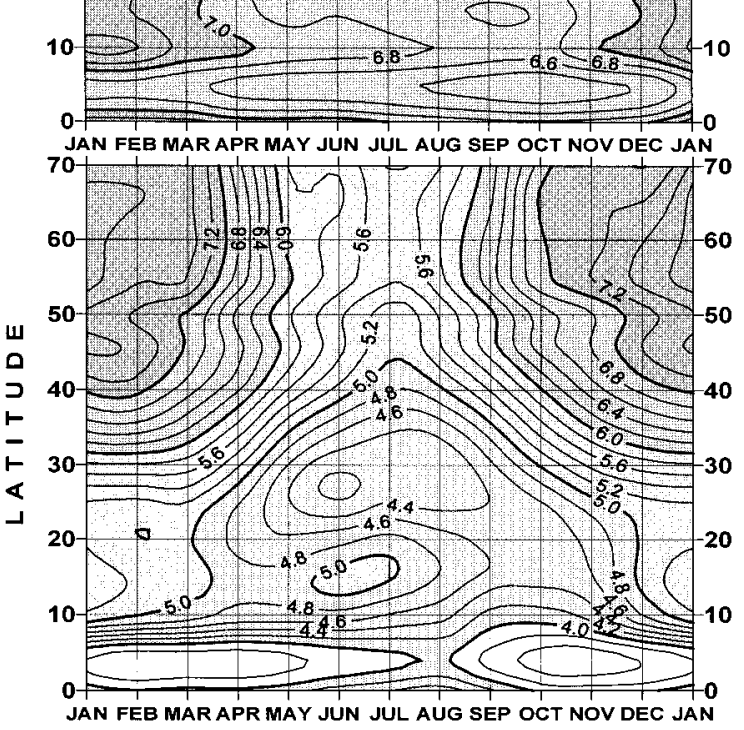

FIG. 10. Annual cycle of zonal averaged sea (a), swell (b), and resultant period (c). Units are seconds.

mation about the height of ship anemometers. Recently Kent and Taylor (1997) and Josey et al. (1996) introduced the merging of COADS individual reports with the WMO47 (WMO 1990) annual lists of the information about VOS characteristics, including anemometer heights. Following Kent and Taylor (1997) we have merged our collection of reports with the WMO47 list by checking the call signs of VOS. For the cases when the COADS call signs did not match the WMO47 list, the anemometer level was assumed to be constant and equal to $25 \mathrm{~m}$ according to Cardone et al. (1990), da Silva et al. (1994), and Kent and Taylor (1997). Then the correction of anemometer winds to a $10-\mathrm{m}$ standard level and neutral stability was made using Smith's (1980) method. This correction has reasonably reduced the actually measured wind by from several tenths of a meter for moderate winds to $1-2 \mathrm{~m}$ for strong winds. Estimated winds in the COADS CMR and LMR collection are assumed to be taken at a $10-\mathrm{m}$ reference height according to the old WMO code 1100 Beaufort equivalent scale (WMO 1970). During recent decades a number of alternative equivalent scales were developed [WMO 1970 (CMMIV); Cardone 1969; Kaufeld 1981; da Silva et al. 1995; Lindau 1995]. Kent and Taylor (1997) made a comprehensive comparison of different Beaufort equivalent scales and found the Lindau (1995) scale to be the most effective for the computation of unbiased winds from Beaufort force estimates. Note here that the old WMO 1100 scale was also found to be appropriate, at least in the comparison with the CMMIV and Kaufeld scales. We converged wind estimates to the Lindau (1995) scale and obtained estimated winds at the 25-m height because the Lindau (1995) scale was established for this level. Then we applied a correction for the 10-m height and neutral stability to these winds as described above.

According to the recommendations of Dobson et al. (1994) we eliminated those reports that give $|\vartheta|>30^{\circ}$, when sea was not in wind direction. Relative contributions of such reports decrease from the beginning to the end of the observational period and in the majority of cases is lower than 5\%. In general, the difference between true and effective wind is smaller than $0.3 \mathrm{~m}$ $\mathrm{s}^{-1}$. Following Dobson et al. (1994) and Smith et al. (1992), we also eliminated those reports that give $a>$ 1.2. These omitted reports contribute another $0.1 \%-3 \%$ to the total amount of omitted observations. Figure $2 \mathrm{c}$ shows the interannual variability of the relative number of reports omitted due to both described quality controls. Their number is always less than $20 \%$ and significantly decreases in the late 1960s, 1970s, and 1980s when the typical number of deleted reports ranges from $1 \%$ to $6 \%$. Approximately $95.5 \%$ of all reports with wave observations were accepted for the calculations of wave age according to (3) and (4) and for the evaluation of the wind stress.

Smith (1991) on the basis of selected cases from videotapes with single wave trains introduced a "neutral drag coefficient anomaly," which represents the departure of neutral drag $C_{V n}$ due to its dependence on wave age. Following Smith (1991) and Smith et al. (1992), this anomaly can be computed from wave age as

$$
10^{3} \delta C_{n}=1.85-2.24 a \text {. }
$$

Both HEXOS (Smith et al. 1992) and ERS-1 SAR (Dobson et al. 1994) experiments gave evidence of the general agreement with Smith's (1991) results. Anomaly 

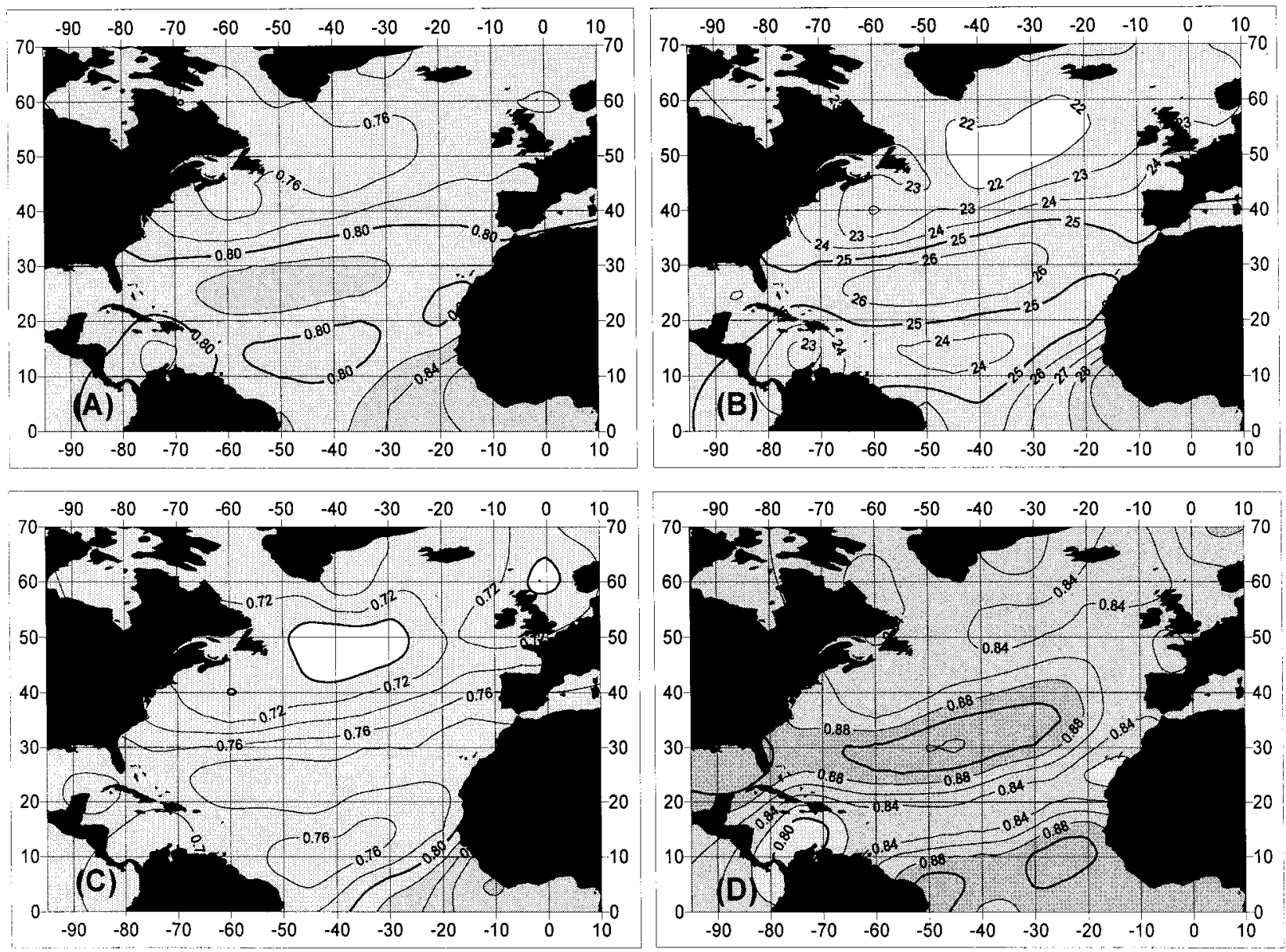

FIG. 11. Annual mean wave age estimates $a=C_{p} / V_{\text {ef }}$ (a) and $a_{*}=C_{p} / u_{*}$ (b), and monthly mean wave age $a=C_{p} / V_{\text {ef }}$ for January (c) and July (d).

(7) represents the departure of the neutral drag coefficient from Smith (1988), computed with the Charnock (1955) formula. Equation (7) gives zero departure at a wave age of 0.83 . For every individual report we applied anomaly (7) to the neutral drag coefficient of Smith (1988) and computed a revised drag coefficient, which has been taken for the computations of the wind stress and its components:

$$
\tau=\rho_{a} C_{V} V^{2}, \quad \tau_{x}=\rho_{a} C_{V} V V_{x}, \quad \tau_{y}=\rho_{a} C_{V} V V_{y} .
$$

A number of parameterizations of drag coefficients is based on the alternative wave age estimate (2). Smith et al. (1992) studied, on the basis of HEXOS results, the relationship of surface roughness $z_{0}$ to wave age $a_{*}$. He found, that the dependence of roughness on wave age can be defined by a regression:

$$
z_{0}=\mu u_{*}^{3} / g C_{p}=\left(\mu u_{*}^{2} / g\right) a_{*}^{-1},
$$

with $\mu=0.48$ (Smith et al. 1992). This estimate gives another means to evaluate neutral drag, dependent on both wind speed and wave age. The dependencies of roughness on the alternative wave age estimate (4) were evaluated by Donelan (1990), Smith et al. (1992), and Donelan et al. (1993). Smith et al. (1992) notes that Eq. (9) is possibly influenced by self-correlation through scaling with the friction velocity. At the same time, in Eq. (7) self-correlation is avoided. We also computed wind stress estimates based on Eq. (9), although the majority of results in this paper are presented for the drag coefficient computed from the anomaly (7). Dobson et al. (1994) showed that the open ocean relation between sea state and wind stress in the presence of swell do not differ much from those obtained without swell. We have obtained an additional estimate of the wind stress based on only those cases when sea was a dominant process. We have selected for each individual month only those reports that indicate sea higher than swell by at least $50 \%\left(h_{w} / h_{s} \geq 1.5\right)$. Then we computed a sea-state-dependent stress using (7) on the basis of only these cases. For all other cases (sea either equal to or lower than swell) stress was computed traditionally using Smith's (1988) parameterization. Individual estimates of wave age and sea-state-based wind stress 
computed from different parameterizations were averaged into $5^{\circ}$ boxes in the same manner as for individual wave and swell parameters.

\section{Wave age and sea-state-dependent wind stress in the North Atlantic}

Figures 11a,b display annual mean charts of wave ages computed using Eqs. (3) and (4) and denoted as $a$ and $a_{*}$. The annual mean wave age indicates the area with the youngest waves in the central North Atlantic midlatitudes. Annual mean values of $a$ here are from 0.74 to 0.76 . A tropical minimum in the trade wind zone is characterized by wave age $0.79-0.81$. The highest annual values in the subtropics and in the equatorial area vary from 0.82 to 0.85 , and frequently overpredict the 0.83 value, which gives zero anomaly of neutral drag coefficient (Smith et al. 1992; Dobson et al. 1994). Spatial patterns of the annual distribution of wave age estimate $a_{*}$ do not differ very much from those for $a$ and indicate more pronounced features in the Tropics and subtropics. January and July charts of wave age estimate $a$ (Figs. 11c,d) indicate a pronounced annual cycle everywhere in the North Atlantic. The youngest waves in winter are characterized by values from 0.68 to 0.71 in midlatitudes. Summer values are higher than 0.83 practically everywhere, except for a very limited area in the midlatitudes and in the Tropics. The highest wave age, ranging from 0.90 to 0.92 , appears during summer months in equatorial areas. The seasonal cycle for zonal averages of $a$ is shown in Fig. 12 and indicates that greatest month-to-month changes take place during spring and autumn when wave age drops from $0.85-$ 0.89 to $0.75-0.80$ during one month, which accounts for about $75 \%$ of annual variation. Minimum zonal means smaller than 0.7 are observed in December in midlatitudes. Maximum summer values in the subtropics range from 0.88 to 0.90 .

Figures 13a,b show the annual mean wind stress, taken traditionally according to (8) and on the basis of Smith's (1991) parameterization (7). Wind stress taken from the Smith (1991) parameterization exceeds that computed traditionally by $10 \times 10^{-3}$ to $25 \times 10^{-3} \mathrm{~N}$ $\mathrm{m}^{-2}$ in midlatitudes and in the Tropics. Subtropical and equatorial climatological values are very close to each other, when computed traditionally and on the basis of the wave age. Charts of the ratios between different estimates of the stress with and without considering wave age for individual months are shown in Figs. $13 \mathrm{c}, \mathrm{d}$. In winter Smith's (1991) estimate is from 3\% to $20 \%$ higher than traditional. A maximum of the ratio between the two estimates is located in the midlatitudinal northwest Atlantic, where the ratio closely matches 1.20. In July, when waves become significantly more developed, the ratio ranges from 0.93 to 1.08 . In the subtropics and in the equatorial area the ratio between Smith (1991) and traditional estimates is less than 1, indicating higher values of stress taken traditionally. A

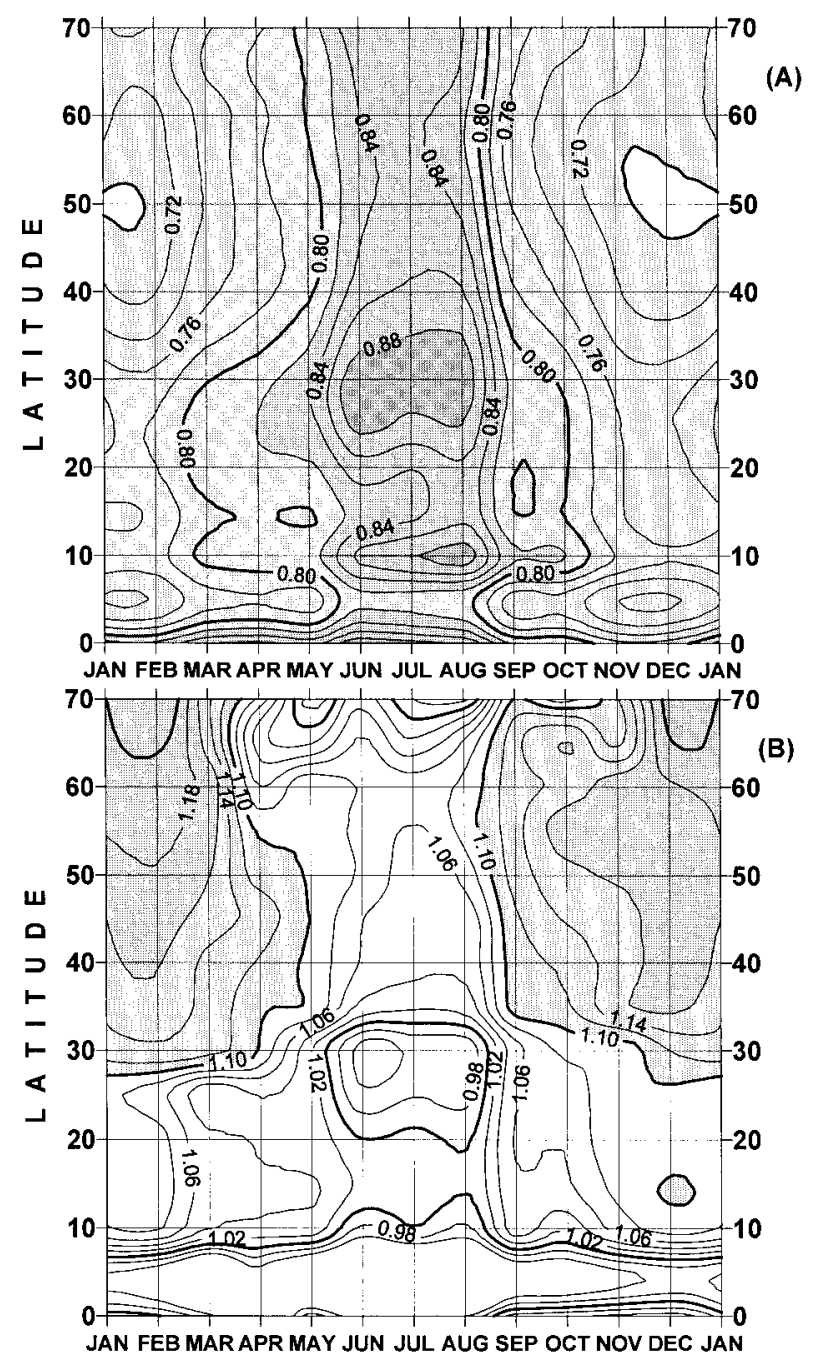

FIG. 12. Annual cycle of zonal averaged wave age parameter $a=$ $C_{p} / V_{\text {ef }}$ (a) and of the ratio between Smith (1991) and traditional estimates of wind stress (b).

time-latitude diagram of zonal averages of the ratio between Smith's (1991) and the traditional estimate of wind stress (Fig. 12b) demonstrates that over the whole North Atlantic north of $10^{\circ} \mathrm{N}$ and during practically the whole year, except for three summer months south of $35^{\circ} \mathrm{N}$, the Smith values are higher by 3\%-18\%. If we compare east and north components of wind stress, taken traditionally with those computed with Smith's (1991) method (Fig. 14), there will be major differences for the east component, which indicates from $10 \times 10^{-3}$ to $20 \times 10^{-3} \mathrm{~N} \mathrm{~m}^{-2}$ larger positive values in midlatitudes and from $5 \times 10^{-3}$ to $15 \times 10^{-3} \mathrm{~N} \mathrm{~m}^{-2}$ stronger negative $\tau_{x}$ in the tropical area, when computed with the wave-age-based approach. Differences for the north component of wind stress are small and range from $10^{-3}$ to $4 \times 10^{-3} \mathrm{~N} \mathrm{~m}^{-2}$. Zonal averages in Fig. 15 show that the midlatitudinal maximum of the positive east component of wind stress, computed with the Smith 

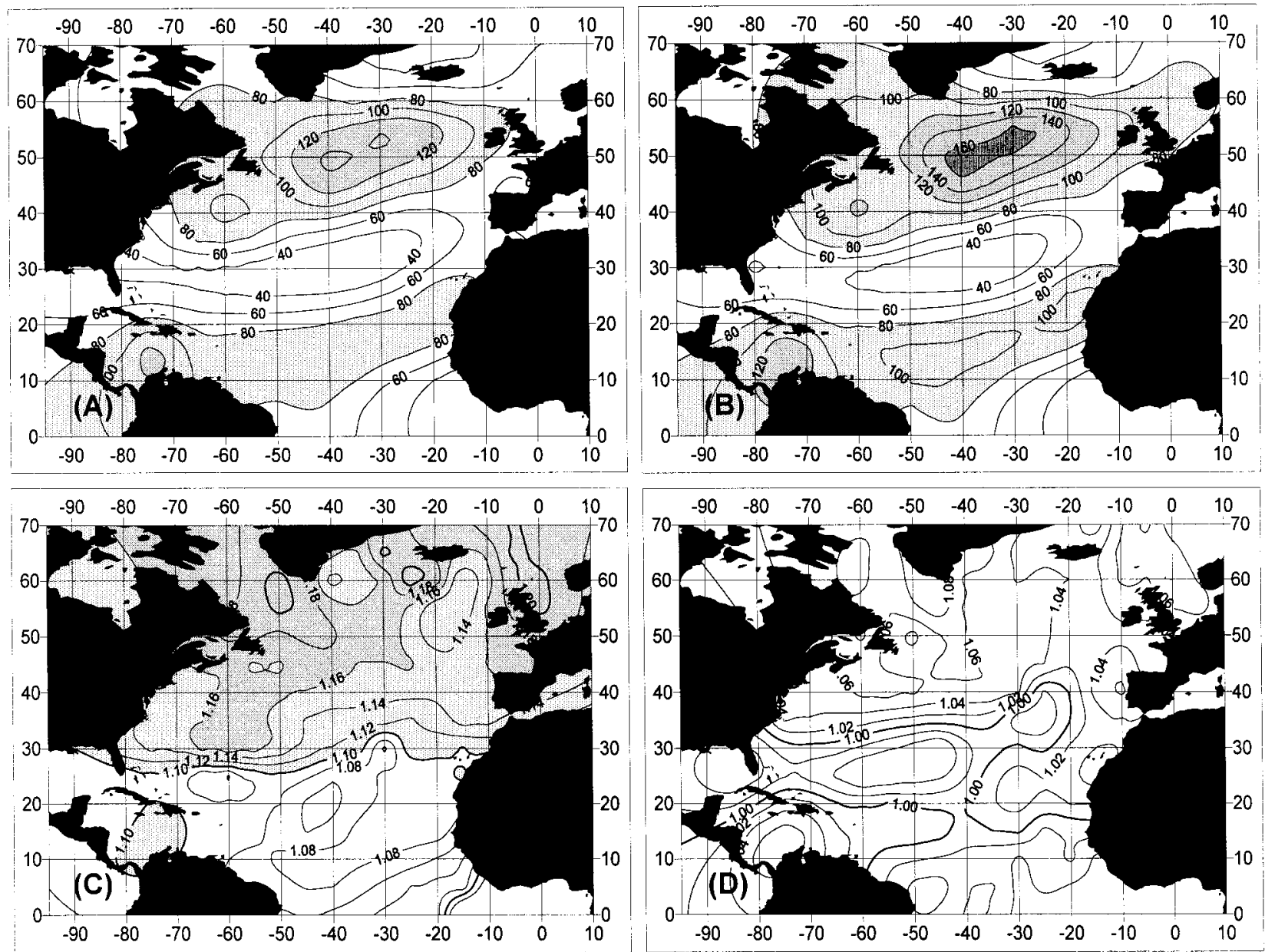

FIG. 13. Annual mean wind stress $\left(10^{-3} \mathrm{~N} \mathrm{~m}^{-2}\right.$ ) computed traditionally (a) and using the Smith (1991) method (b). January (c) and July (d) maps of the ratio between Smith (1991) and traditional estimates of wind stress.

(1991) method, is nearly $22 \%$ higher than those taken traditionally. In the Tropics Smith's (1991) method gives $10 \%-15 \%$ stronger negative values in comparison with traditional estimates. Thus, we conclude that the impact of sea state on the stress estimates, computed with the Smith (1991) method, at least in midlatitudes and during the winter season has a remarkable climatological effect.

We have evaluated additional estimates of the wind stress on the basis of only cases when sea was significantly more pronounced than swell. Dobson et al. (1994) and Hanson (1996) have developed methods of the spectral partitioning of sea and swell. Visual observations give separate estimates of sea and swell. Figure 16a shows the percentage of cases when sea was significantly higher than swell $\left(h_{w} / h_{s} \geq 1.5\right)$, which varies from a minimum of $11 \%-12 \%$ in the central midlatitudinal Atlantic to about $25 \%$ in the western Atlantic. Although spatial patterns for individual seasons (not shown here) are similar for the climatological picture in Fig. 16a, there is a seasonal dependence with higher values in winter $(16 \%-38 \%)$ and smaller percentages in summer $(6 \%-20 \%)$. Climatological mean wave age es- timate $a$ computed from only these selected cases is shown in Fig. 16b. Wave age values are from 0.02 to 0.06 smaller than those computed from all cases and indicate a minimum of about 0.70 in the northwest Atlantic and a maximum of 0.82 in the equatorial area. Wind stress for these cases was computed using formula (7), and for all other cases using traditional Smith (1988) drag coefficient. Then all estimates were averaged in the same manner as for other estimates to produce climatology. The result is shown in Fig. 16c in terms of the ratio between wave age-based wind stress and a traditional estimate. Values of this ratio in midlatitudes are reasonably smaller than those for the ratio computed on the basis of all cases by approximately 0.03-0.05. Maximum ratios of $1.12-1.14$ are located in the midlatitudinal northwest Atlantic and in the Norwegian Sea where the percentage of cases with $h_{w} / h_{s} \geq 1.5$ is higher than in the central part of the North Atlantic.

\section{Errors and uncertainties}

There are a number of errors and uncertainties in our estimates of individual wave variables and wave-age- 

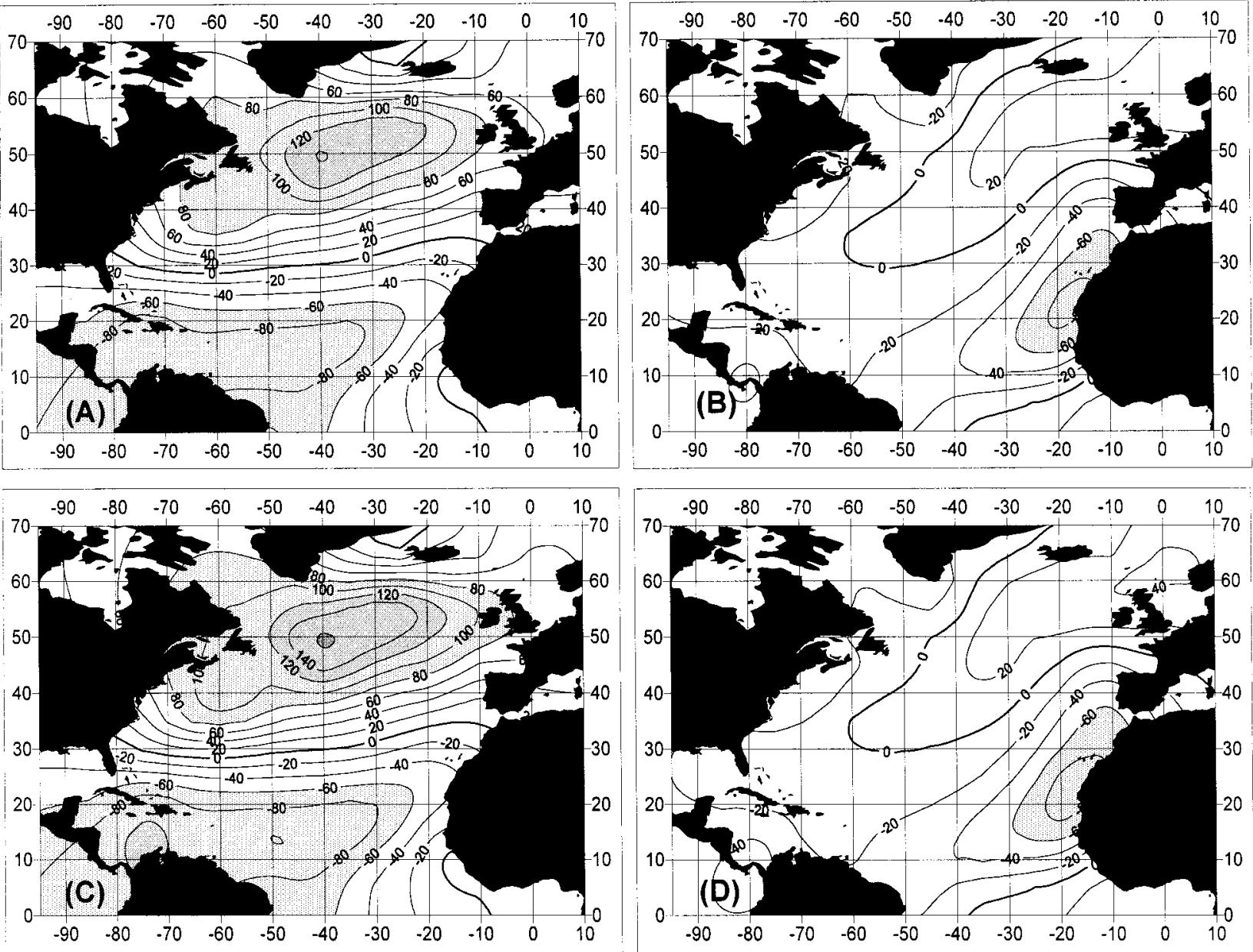

FIG. 14. Annual mean east $(\mathrm{a}, \mathrm{c})$ and north $(\mathrm{b}, \mathrm{d})$ component of wind stress $\left(10^{-3} \mathrm{~N} \mathrm{~m}^{-2}\right)$ computed traditionally (a, b) and using Smith (1991) method (c, d).

based products. There are different views on the reliability of visual estimates taken by VOS. On one hand, there is evidence of inaccuracy of the visual estimation technique (Hogben and Lumb 1967; Jardine 1979; Hogben et al. 1983; Wilkerson and Earle 1990; Hogben 1995). On the other hand, wave parameters observed visually should not be much worse than Beaufort estimates of wind speed, which are still a considerable contribution of about $70 \%-80 \%$ of the total number of marine wind observations. Sailors, estimating Beaufort force, use the characteristics of the sea state, and the sea surface is always under considerable attention of the observers. In order to evaluate observational accuracy of visual estimates, we used visual observations at OWS vessels and from the Sections field program in the northwest Atlantic (Gulev 1994). These observations are done by technicians, who are much better trained than the VOS observers. Hogben and Lumb (1967) and Hogben et al. (1986) compared OWS J visual data with the VOS visual estimates and found both systematic and random errors in the VOS observations. At the same time, they used data from a $5^{\circ} \times 10^{\circ}$ box around the OWS vessel. This area grossly overestimates the size of even 0.2 correlation ellipse. Thus, differences obtained may result from the natural space variability and sampling errors. We compared OWS visual observations with the VOS data within a certain spatial correlation ellipse. Actual values of the correlation level varied for different OWS and time periods from 0.82 to 0.94 to provide at least $100 \mathrm{VOS}$ observations per month within selected ellipse. The comparison was made for the period of overlap of OWS and SECTIONS data with VOS observations, excluding the year of 1969 for swell periods. Table 3 shows results of the comparison for OWSs C, D, E, I, J, and M. Standard deviations of the differences in sea and swell heights vary within the range of $1 \mathrm{~m}$, and std dev of periods are within the range of 1 s. Swell periods from OWS and VOS match each other better than those for sea periods. Our estimates of std dev of "OWS minus VOS" differences are nearly twice as small as those obtained by Hogben and Lumb (1967), 


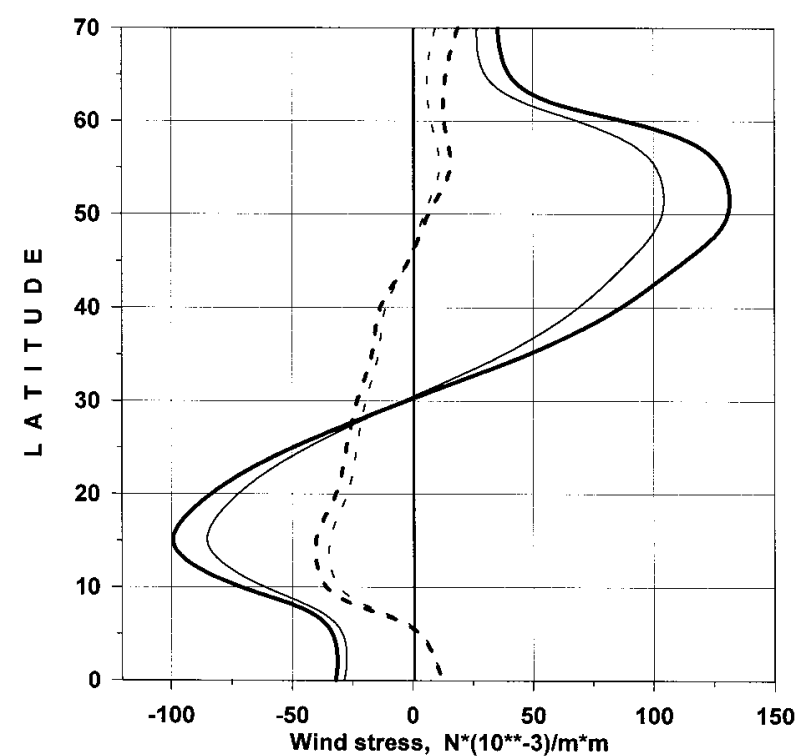

FIG. 15. Annual zonal means of the east (solid lines) and the north (dashed lines) components of wind stress computed traditionally (thin lines) and using Smith's (1991) method (bold lines).

Hogben and Tucker (1994), and Hogben (1995) from a large $5^{\circ} \times 10^{\circ}$ area around OWS J.

To obtain error estimates of our results we estimated random observational and sampling errors in the computed wave age. We used a method from Weare's (1989), based on a Monte Carlo generation of random errors in observations. Cayan (1992) applied this method to the estimated errors in his heat flux calculations and found errors to be strongly connected with a number of samples. In our case, errors of wave age estimates (3), (4) are caused from observational errors of fundamental observations, such as scalar wind speed, wind direction, wave period, wave direction. To set appropriate ranges of observational error generation we used the results of the VSOP-NA project (Kent et al. 1993). For wind speed and wind direction we can take from 1 to $2 \mathrm{~m} \mathrm{~s}^{-1}$ and $\pm 10^{\circ}$, as recommended by Kent et al. (1993). Taking into account general agreement of wave direction with wind direction (cases with higher than a $30^{\circ}$ departure of these directions from each other were omitted), we can also take $\pm 10^{\circ}$ as an observational error for wave direction. For visually observed wave periods we selected ranges from 1 to $2.5 \mathrm{~s}$ on the basis of the comparison with instrumental measurements (Table 1) and OWS data (Table 3). Then we generated for the actual observations random errors bounded by selected ranges of observational error. Figure 17a demonstrates errors computed for January for three Marsden squares in the northeast Atlantic as a function of the number of samples within a $5^{\circ} \times 5^{\circ}$ box and an individual January. The region selected and the season are characterized by the greatest variability of the parameters involved in the computations. So we expect that in the other regions and months error estimates will be lower. For 100 sam-
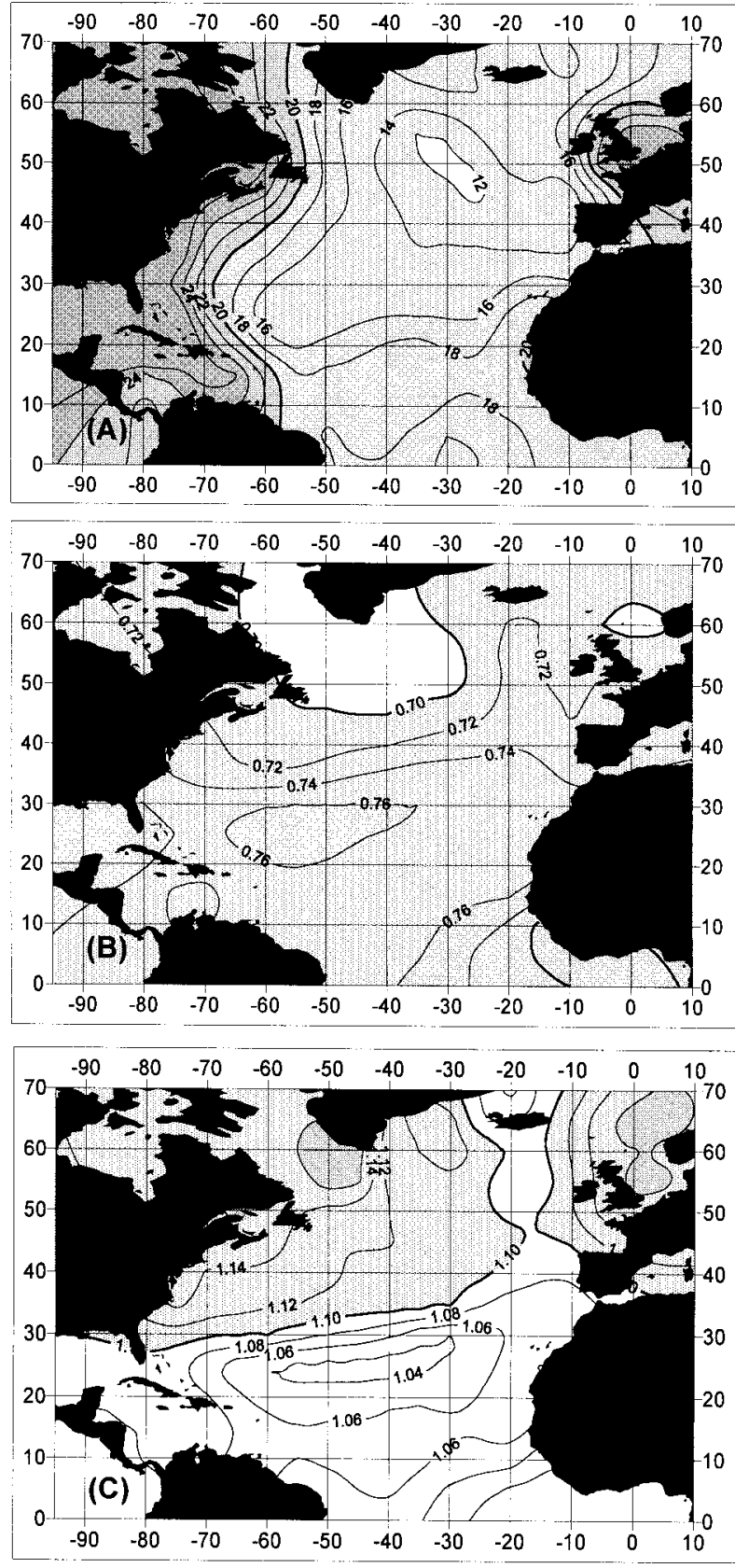

FIG. 16. Percentage of cases $h_{w} / h_{s} \geq 1.5$ (a), annual mean wave age computed on the basis of only these cases (b), and the ratio between wave age-based wind stress [computed using Smith's (1991) method for $h_{w} / h_{s} \geq 1.5$ and traditionally for all other cases] and traditional wind stress estimate (c).

ples the observational error of $a$ becomes about 0.025 for wind speed observational accuracy of $2 \mathrm{~m} \mathrm{~s}^{-1}$ and wave period accuracy of $2.5 \mathrm{~s}$. For the $1 \mathrm{~m} \mathrm{~s}^{-1}$ and 1$\mathrm{s}$ accuracies we get for $n=100 \mathrm{std}$ dev error of 0.0118 . The corresponding error estimates for 300 samples are 0.02 and 0.009 , and for 600 samples are 0.017 and 0.01 . The number of samples for an individual month is usually higher than 200-300, and for multiannual clima- 
TABLE 3. OWS minus VOS and SECTIONS minus VOS differences in wave heights $(\mathrm{m})$ and wave periods (s) for selected OWS. Top numbers are mean differences, bottom numbers are std dev of differences.

\begin{tabular}{|c|c|c|c|c|}
\hline \multirow[b]{2}{*}{ OWS } & \multicolumn{2}{|c|}{$\begin{array}{c}\text { Differences in wave } \\
\text { variables }\end{array}$} & \multirow[b]{2}{*}{$\begin{array}{l}\text { Swell } \\
\text { height }\end{array}$} & \multirow[b]{2}{*}{$\begin{array}{l}\text { Swell } \\
\text { period }\end{array}$} \\
\hline & $\begin{array}{c}\text { Sea } \\
\text { height }\end{array}$ & $\begin{array}{c}\text { Sea } \\
\text { period }\end{array}$ & & \\
\hline \multirow[t]{2}{*}{$\mathrm{C}$} & 0.21 & -0.19 & 0.36 & 0.04 \\
\hline & 0.57 & 0.73 & 0.89 & 0.61 \\
\hline \multirow[t]{2}{*}{$\mathrm{D}$} & 0.09 & 0.13 & 0.28 & -0.07 \\
\hline & 0.37 & 1.06 & 0.55 & 0.47 \\
\hline \multirow[t]{2}{*}{$\mathrm{E}$} & -0.12 & 0.11 & -0.25 & -0.18 \\
\hline & 0.27 & 0.34 & 0.59 & 0.82 \\
\hline \multirow[t]{2}{*}{ I } & 0.00 & -0.05 & -0.22 & -0.24 \\
\hline & 0.40 & 0.19 & 0.62 & 0.41 \\
\hline \multirow[t]{2}{*}{$\mathrm{J}$} & 0.38 & 0.39 & 0.17 & 0.14 \\
\hline & 0.86 & 0.62 & 0.33 & 0.51 \\
\hline \multirow[t]{2}{*}{ M } & -0.06 & -0.15 & -0.43 & 0.11 \\
\hline & 0.24 & 0.74 & 1.19 & 0.32 \\
\hline \multirow[t]{2}{*}{ Sections } & 0.14 & 0.22 & 0.03 & 0.16 \\
\hline & 0.41 & 0.59 & 0.49 & 0.52 \\
\hline
\end{tabular}

tological months is larger than several thousand. Thus, for our seasonal and climatological products, random observational error in $a$ is expected to be within 0.015 for wintertime and midlatitudes and should be significantly lower in other regions and seasons.

To estimate inadequate sampling error (Legler 1991; Cayan 1992), we selected a different random number of reports for each $5^{\circ} \times 5^{\circ}$ box within Marsden squares $80,110,114,116,146$ and 147, 149, 252, characterized by a high number of observations. To ensure that the original number of reports gives nearly errorless variables statistics, we used only those months that have more than 700 observations within a $5^{\circ} \times 5^{\circ}$ box. Sampling error depends on the level of the spatial correlation and on the degree of the anisotropy of the two-dimensional spatial correlation functions for selected areas. Figure 17b shows the behavior of sampling error with a number of samples for different regions. If the spatial correlation of wave parameters and of wind is high, the sampling error in the wave age varies from 0.018 to 0.022 for 200 samples, and from 0.013 to 0.018 for 600 samples. For regions with lower spatial correlation, the sampling error is slightly higher than the observational error (Fig. 17a) and gives, for say 300 samples, 0.020.03 . Thus, for the eastern and western subtropical Atlantic and for the Norwegian Sea we can expect 20\%$30 \%$ higher sampling errors than for open ocean regions. When we consider the products for climatological months, the number of observations exceeds usually several thousand, and the sampling error drops to less than 0.01. If we combine observational and sampling error, assuming the coupled error to be approximately the sum of the individual errors, we get 0.02 to 0.035 error in wave age estimates for individual months and from 0.01 to 0.015 error for climatological products. This is several times smaller than the obtained range of
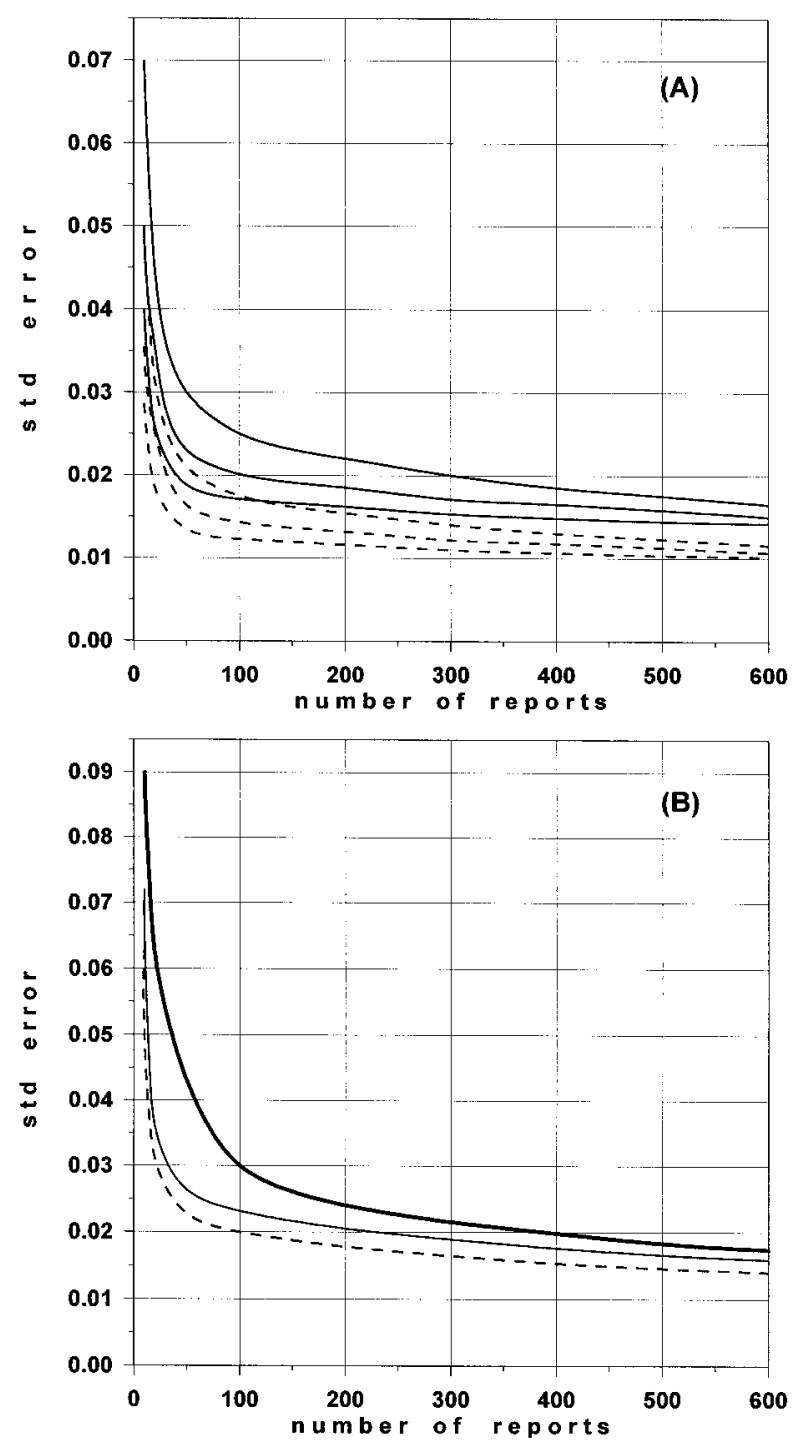

FIG. 17. (a) January random observational error in the wave age for wind speed observational error $2 \mathrm{~m} \mathrm{~s}^{-1}$ (solid lines) and $1 \mathrm{~m} \mathrm{~s}^{-1}$ (dashed lines). In each set of lines, lines from the top to the bottom correspond to $2.5,1.5$, and $1 \mathrm{~s}$ observational error in wave period. (b) January sampling error for $5^{\circ}$ box averaged over Marsden squares 110 (bold line), 116 (thin line), and 114 (dashed line).

spatial variability of $a(0.06-0.09)$ and than the seasonal variation (0.05-0.08). Thus, principal features of the variability of the wave age appear to be reliable. We did not estimate nonrandom errors, caused from the methods we used because of incomplete information about the accuracy of parameterizations given by different authors. Smith et al. (1992) and Dobson et al. (1994) give estimates of the correlations about their regressions lines, but this is not enough yet to estimate the nonrandom errors. Experience shows that such errors could be rather high, even for relatively well-developed "traditional" parameterizations of sea-air fluxes (Blanc 1987; Isemer et al. 1989; Gulev 1995; Kent and Taylor 1995). 


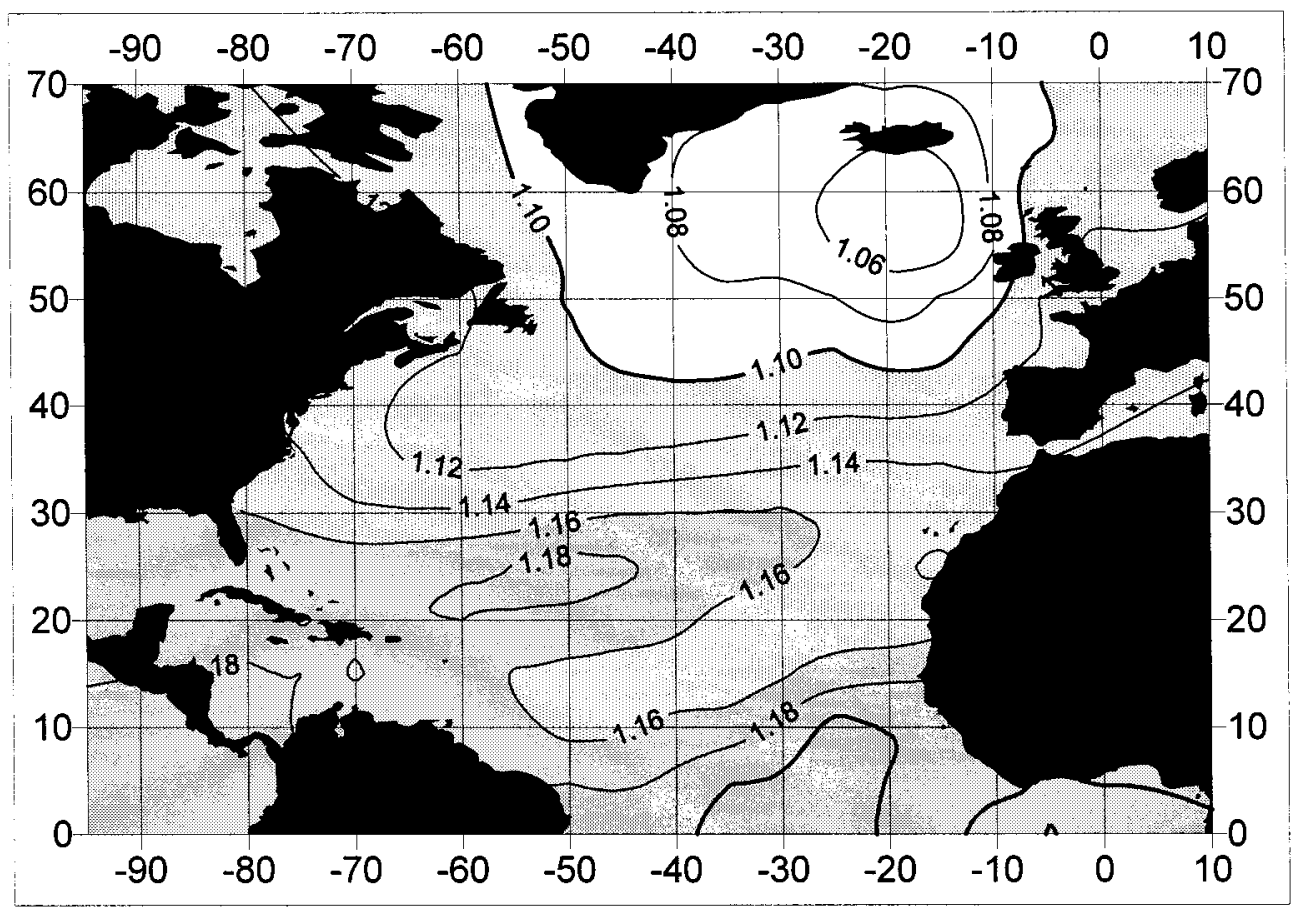

FIG. 18. Annual mean ratio between Geernaert et al. (1987) and traditional estimates of wind stress

\section{Discussion}

Our results based on visual observations can be discussed from a number of viewpoints. The spectrum of approach to visual estimates among officers is quite wide: ranging from really precise attention to the wave field with the use of a special plane and watch to just short seaward looks, if only made by very experienced sailors. In this context it is important to make a comprehensive evaluation of the actual accuracy of visual observations by designing special observational projects, like the Voluntary Ship Observational Project in the North Atlantic for basic meteorological variables (Kent et al. 1993), and special questionnaires to be distributed among ship officers. Of great importance is the continuity of the validation efforts against different in situ measurements. Our climate of wave parameters does not indicate any strong disagreement with known and expected wind field features, so there is not much point in rejecting it completely. We have at the moment no other source of information about the wave fields with such space-time resolution for a long period as the COADS collection. Moreover, when using these data it is possible to separate sea from swell, which is especially important for wind stress estimates. During recent years there was considerable debate about the reliability of long-term wind speed trends, indicated by COADS, ranging from 0.1 to $0.5\left\langle\mathrm{~m} \mathrm{~s}^{-1}\right\rangle$ per decade (Ramage 1984; Peterson and Hasse 1987; Cardone et al. 1990; Lindau et al. 1990; Ward 1992; Bigg 1993; Isemer 1995; Diaz et al. 1995). Changes with time of the relative role of anemometer measurements are con- sidered as one of the possible reasons for unrealistically high COADS wind trends. In this context wind waves, as an integrated space-time characteristic of wind speed, can give a relevant background for investigating the reliability of wind trends, especially if both climatologies are taken from the same information source, such as COADS. Recently Cardone et al. (1994) found a positive correlation between zonal wind index and wave height from a model hindcast for winter months in the 1980s that is in agreement with Kushnir's (1994) analysis of North Atlantic ocean-atmosphere interaction and circulation changes. Thus, observed for long periods, waves could be considered as an important independent indicator of climate variability in general.

Our wave age and wind stress calculations give evidence of the possible climatological significance of the impact of sea state on wind stress. Of extreme importance is to attend such estimates with nonrandom errors, caused from parameterizations of drag coefficient dependence on wave age. At the same time, wave age estimates by themselves can be used in many ways. Some other parameterizations of the sea-state-based wind stress can be tested on the basis of obtained wave age fields. For comparison, we have computed wind stress on the basis of the parameterization from the MARSEN field experiment (Geernaert et al. 1987; Geernaert 1990), which gives for the neutral drag the following dependence on the wave age estimate $a_{*}$ :

$$
C_{V n}=0.012 a_{*}^{-2 / 3} .
$$

An annual mean chart of the ratio between the Geer- 
naert et al. (1987) and the traditional estimate is shown in Fig. 18. In the tropical area, the Geernaert et al. (1987) method gives significantly higher values of the wind stress than those computed using Smith's (1991) approximation. Due to the impact of $C_{V}$ on $a_{*}$, the Geernaert et al. (1987) estimate is influenced by self-correlation through scaling of $C_{p}$ with friction velocity. Thus, ratios in Fig. 18 have a pronounced meridional dependence with a general tendency of increasing in the Tropics and equatorial area, where they reach 1.15-1.20 values. Experiments with the ocean wave model (WAM) coupled with the atmospheric GCM (Weber et al. 1993) show that the effect of wave-induced stress is small and appears in the area of the Southern Ocean storm track and particularly in the North Atlantic tropical area where it contributes $15 \%-20 \%$ to the total stress. In this context Fig. 18 shows general agreement with the Weber et al. (1993) results in the tropical Atlantic. On the other hand, our estimates of the wave-induced stress obtained using Smith's (1991) method in midlatitudes (Fig. 13) are significantly larger than those obtained in model experiments of Weber et al. (1993).

Impact of the sea state on wind stress can have profound implications for evaluation of the wind-driven circulation in ocean models. We applied the obtained wind stress estimates to the calculation of Ekman volume transport and Ekman meridional heat transport to determine whether any differences appear in these important climatological parameters when computed with wave-dependent stress. Although not all of the momentum loss to the waves is available to the ocean (Weber 1994), the WAM-ECHAM (European Centre Hamburg Model) model shows that the remainder, dissipating in the local waved field, is not higher than 5\% for young waves (S. Weber 1995, personal communication). Thus we can obtain the highest possible estimate of the sea state influence on the Ekman transport in the ocean. Meridional Ekman volume and heat fluxes were computed as

$$
E V_{Y}=-\tau_{x} / f \rho, \quad E H_{Y}=-c_{p}\left(T_{w}-\theta\right) \tau_{x} / f,
$$

where $f$ is the Coriolis parameter, $\rho$ is the density of sea water, $c_{p}$ is the specific heat of sea water, and $\theta$ is the annual vertical mean potential temperature, taken from Levitus (1987). We computed Ekman volume transports and Ekman heat transports from (11) and then integrated the obtained values over the North Atlantic latitudinal belts, as recommended by Levitus (1987, 1988). Figures 19a,b shows Ekman volume and heat transports computed traditionally and with the use of Smith's (1991) parameterization of drag coefficient. Seasonal Ekman volume transport (not shown here) computed with the revised wind stress gives 6\%-13\% higher tropical values and $12 \%$ stronger negative midlatitudinal values in winter. If we consider mean climatological curves of the meridional Ekman volume and heat transports, taken with traditional and wavebased wind stress for the period 1964-93 (Fig. 19), the
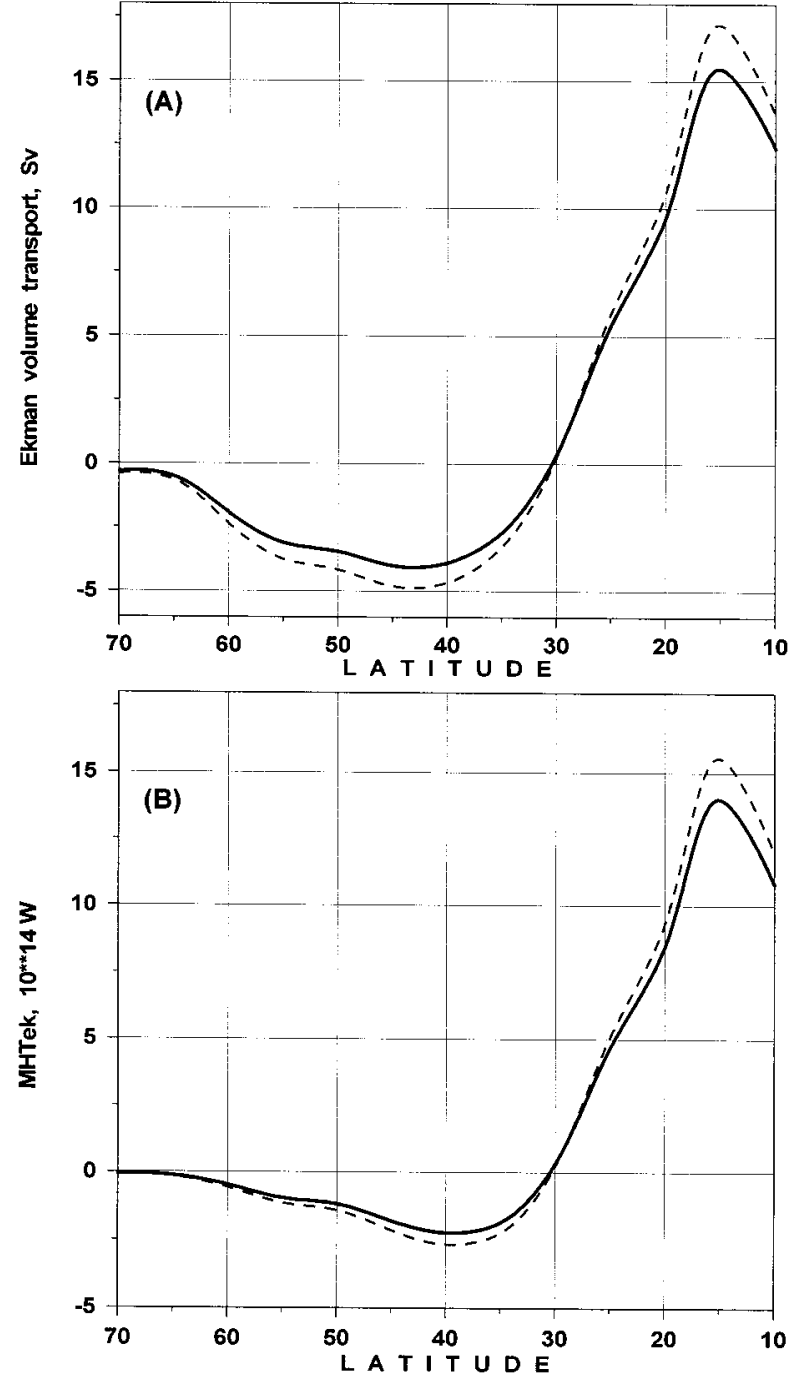

FIG. 19. Annual zonal-mean meridional Ekman volume transport (Sv) (a) and meridional Ekman heat transport $\left(10^{14} \mathrm{~W}\right)(\mathrm{b})$, computed traditionally (solid lines) and with wind stress estimated by Smith (1991) method (dashed lines).

tropical maximum indicates nearly $10 \%$ higher values of the Ekman transport when computed on the basis of wave age. Concerning this comparison, we can note that Boening et al. (1991) made experiments with an eddy resolution circulation model forced by Isemer and Hasse (1987) wind stress and Hellerman-Rosenstein (1983) wind stress. They obtained significant differences in the intensity of subtropical gyre of the North Atlantic in two experiments forced by different stresses. One of the possible lines of future investigations is connected with the evaluation of other important wave-based climatological parameters. For example, Preisendorfer and Mobley (1986) found albedo of the sea surface to be dependent on wave parameters in addition to sun declination and cloudiness. Perhaps some other radiation 
characteristics could be better evaluated if computed taking into account the state of the sea surface.

Acknowledgments. This study was performed during the periodical work of SKG at IFM (Kiel) in 1994 and 1995. He thanks IFM for its hospitality. Special thanks to Dr. J. Kielmann for his support of our work on the IFM computer cluster. Individual COADS data were made available by courtesy of Steve Worley of NCAR (Boulder). During this work we had extremely helpful discussions with Fred Dobson and Stuart Smith of BIO (Dartmouth), Neil Hogben of BMT, Ltd. (Teddington), and Andreas Sterl and Nanne Weber of KNMI (de Bilt). The suggestions and criticism of three anonymous reviewers are greatly appreciated. Great thanks to Anne Meyer, who helped us very much by doing her excellent and important everyday job. This study was supported by Deutsche Forschungsgemeinschaft, Sonderforschungsbereich SFB 133.

\section{REFERENCES}

Bacon, S., and D. J. T. Carter, 1989: Waves recorded at Seven Stones Light vessel 1962-86. Report No. 268, IOS, Deacon Laboratory, NERC, Wormley, 94 pp. [Available from Southampton Oceanography Centre, Southampton, SO14 3ZH, United Kingdom.]

_, and _ 1991: Wave climate changes in the North Atlantic and North Sea. Int. J. Climatol., 11, 545-588.

— atmospheric pressure gradient in the North Atlantic. Int. J. Climatol., 13, 423-436.

Barratt, M. J., 1991: Waves in the North East Atlantic. U.K. Department of Energy Report OTI 90545, HMSO, London, 16 pp. +40 fig.

Bauer, E., S. Hasselmann, K. Hasselmann, and H. S. Graber, 1992: Validation and assimilation of SEASAT altimeter wave heights using the WAM wave model. J. Geophys. Res., 97, 12 67112682 .

Bigg, G. R., 1993: Comparison of coastal wind and pressure trends over the tropical Atlantic: 1946-1987. Int. J. Climatol., 13, 411421.

Blanc, T. V., 1987: Accuracy of bulk-method-determined flux, stability, and sea surface roughness. J. Geophys. Res., 92, 38673876.

Boening, C., R. Doesher, and H.-J. Isemer, 1991: Monthly mean wind stress and Sverdrup transports in the North Atlantic: A comparison of the Hellerman-Rosenstein and Isemer-Hasse climatologies. J. Phys. Oceanogr., 21, 221-235.

Bruning, C., S. Hasselmann, K. Hasselmann, S. Lehner, T. Gerling, 1994: A first evaluation of ERS-1 synthetic aperture radar wave mode data. Global Atmos. Ocean Syst., 2, 61-98.

Campbell, W. J., E. J. Josberger, and N. M. Mognard, 1994: Southern Ocean wave fields during the austral winters, 1985-1988, by GEOSAT radar altimeter. The Polar Oceans and Their Role in Shaping the Global Environment. Geophys. Monogr., No. 85, Amer. Geophys. Union, 421-434.

Cardone, V. J., 1969: Specification of the wind distribution in the marine boundary layer for wave forecasting. Report TR69-1, New York University, New York, NY, 131 pp.

_ J. J. Greenwood, and M. A. Cane, 1990: On trends in historical marine wind data. J. Climate, 3, 113-127.

,-- Y. Kushnir, and M. A. Cane, 1994: Link between North Atlantic wave climate and circulation changes. Proc. Second Int. Conf. on Air-Sea Interaction, Meteorology and Oceanology in Coastal Zone, Lisbon, Portugal, Amer. Meteor. Soc., 1-2.
Carter, D. J. T., and L. Draper, 1988: Has the North-East Atlantic become rougher? Nature, 332, 494.

Cayan, D., 1992: Variability of latent and sensible heat fluxes estimated using bulk formulae. Atmos.-Ocean, 30, 1-42.

Chalikov, D. V., and V. K. Makin, 1991: Models of the wave boundary layer. Bound.-Layer Meteor., 56, 83-99.

Charnock, H., 1955: Wind stress on a water surface. Quart. J. Roy. Meteor. Soc., 81, 639-640.

Chelton, D. B., A. M. Mestas-Nuez, and M. H. Freilich, 1990: Wind stress curl and Sverdrup circulation from the SEASAT Scatterometer. J. Phys. Oceanogr., 20, 1175-1205.

Cotton, P. D., and D. J. T. Carter, 1994: Cross calibration of TOPEX, ERS-1, and GEOSAT wave heights. J. Geophys. Res., 99(C12), $25025-25033$.

Dacunha, N. M. C., N. Hogben, and K. S. Andrews, 1984: Wave climate synthesis worldwide. Proc. Int. Symp. on Wave and Wind Climate Worldwide, London, UK, Royal Inst. Naval Architects, $1-11$.

da Silva, A. M., C. C. Young, and S. Levitus, 1995: Toward a revised Beaufort equivalent scale. Proc. Int. COADS Winds Workshop, Kiel, Germany, H. Diaz and H.-J. Isemer, Eds., NOAA-ERL, IFM (Kiel), 270-286.

$\longrightarrow,-$, and $-1994:$ Atlas of Surface Marine Data. Vol. 2. NOAA, $419 \mathrm{pp}$.

Davidan, I. N., L. I. Lopatukhin, and V. A. Rozhkov, 1985: Wind Waves in the World Ocean. Leningrad, Hydrometeoizdat, 256 pp.

de Las Heras, M. M., and P. A. E. M. Janssen, 1992: Data assimilation with a coupled wind-wave model. J. Geophys. Res., 97, 20 26120270.

Diaz, H. F., X. Quan, and C. Fu, 1995: Marine surface wind changes during 1978-1992: An estimation based on COADS. Proc. Int. COADS Winds Workshop, Kiel, Germany, H. Diaz and H.-J. Isemer, Eds., NOAA-ERL, IFM (Kiel), 48-67.

Dobson, F. W., S. D. Smith, and R. J. Anderson, 1994: Measuring the relationship between wind stress and sea state in the open ocean in the presence of swell. Atmos.-Ocean, 32, 61-81.

Donelan, M. A., 1982: The dependence of the aerodynamic drag coefficient on wave parameters. Proc. First Int. Conf. on Meteorology and Air-Sea Interactions of the Coastal Zone, The Hague, Netherlands, Amer. Meteor. Soc., 381-387.

_ 1990: Air-sea interaction. The Sea, Vol. 9A, B. LeMehaute and D. M. Hanes, Eds., J. Wiley and Sons, 239-292.

— F. W. Dobson, S. D. Smith, and R. J. Anderson, 1993: On the dependence of sea surface roughness on wave development. $J$. Phys. Oceanogr., 23, 2143-2149.

Esbensen, S. K., and V. Kushnir, 1981: The heat budget of the global oceans: An atlas based on estimates from marine surface observations. Oregon State University Climatic Research Institute Rep. No. 29, 27 pp. +188 figs. [Available from Oregon State University, Corvallis, OR 97331-2709.]

Geernaert, G. L., 1990: Bulk parameterizations for the wind stress and heat fluxes. Surface Waves and Fluxes. Vol. 1, G. L. Geernaert and W. L. Plant, Eds., Current Theory. Kluwer Academic, 91-172.

_ - K. B. Katsaros, and K. Richter, 1986: Variation of the drag coefficient and it's dependence on sea state. J. Geophys. Res., 91, 7667-7679.

_ - S. E. Larsen, and F. Hansen, 1987: Measurements of the wind stress, heat flux, and turbulence intensity during storm conditions over the North Sea. J. Geophys. Res., 92, 13 127-13 139.

Gulev, S. K., 1994: Influence of space-time averaging on the oceanatmosphere exchange estimates in the North Atlantic mid latitudes. J. Phys. Oceanogr., 24, 1236-1255.

_ 1995: Long-term variability of sea-air heat transfer in the North Atlantic Ocean. Int. J. Climatol., 15, 825-852.

Hanson, J. L., 1996: Wave spectral partitioning applied to the analysis of complex wave conditions in the North Pacific Ocean. Proc. Eighth Conf. on Air-Sea Interaction, Atlanta, GA, Amer. Meteor. Soc., 61-65. 
Hasse, L., R. Lindau, and E. Ruprecht, 1998: Climatological fluxes at the sea surface. Warm Water Sphere of the North Atlantic Ocean, W. Kraus, Ed., Borntraeger, in press.

Hasselmann, K., and Coauthors, 1973: Measurements of wind-wave growth and swell decay during the Joint North Sea Wave Project (JONSWAP). Dtsch. Hydrogr. Z., A8 (Suppl.), 22 pp.

Hastenrath, S., and P. J. Lamb, 1978: Heat Budget Atlas of the Tropical Atlantic and Eastern Pacific Oceans. University of Wisconsin Press, $104 \mathrm{pp}$.

Hellerman, S., and M. Rosenstein, 1983: Normal monthly wind stress over the World Ocean with error estimates. J. Phys. Oceanogr., 13, 1093-1104.

Hogben, N., 1988: Experience from compilation of global wave statistics. Ocean Eng., 15, 1-31.

- 1995: Increases in wave heights over the North Atlantic: A review of the evidence and some implications for the naval architect. Trans. Roy. Inst. Naval Architect. Part A., 137, 93-115.

— nology, HMSO, London, 263 pp.

—, and M. J. Tucker, 1994: Sea-state development during severe storms: Assessment of data and case histories. Underwater Technol., 20, 23-31.

- N. M. C. Dacunha, and K. S. Andrews, 1983: Assessment of a new global capability for wave climate synthesis. Proc. OCEAN '83, San Francisco, CA, IEEE, 1-6.

—,- , and G. F. Oliver, 1986: Global Wave Statistics. Unwin Brothers, $661 \mathrm{pp}$.

Isemer, H.-J., 1995: Trends in marine surface wind speed: Ocean weather stations versus voluntary observing ships. Proc. Int COADS Winds Workshop, Kiel, Germany, H. Diaz and H.-J. Isemer, Eds., NOAA-ERL, IFM (Kiel), 68-84.

—, and L. Hasse, 1985: The Bunker Climate Atlas of the North Atlantic Ocean. Vol. 1: Observations. Springer-Verlag, 218 pp. , and - 1987: The Bunker Climate Atlas of the North Atlantic Ocean. Vol. 2: Air-Sea Interactions. Springer-Verlag, 252 pp.

_ J. Willebrand, and L. Hasse, 1989: Fine adjustment of large scale air-sea energy flux parameterizations by direct estimates of ocean heat transport. J. Climate, 2, 1173-1184.

Janssen, P. A. E. M., 1989: Wave-induced stress and drag of air flow over sea waves. J. Phys. Oceanogr., 19, 745-754.

_ 1991: Quasi-linear theory of wind-wave generation applied to wave forecasting. J. Phys. Oceanogr., 21, 1631-1642.

—, G. J. Komen, and W. J. P. de Voogt, 1987: Friction velocity scaling in wind wave generation. Bound.-Layer Meteor., 38, 2935.

Jardine, T. P., 1979: The reliability of visually observed wave heights. Coastal Eng., 3, 711-723.

Josey, S. A., E. C. Kent, D. Oakley, and P. K. Taylor, 1996: A new global air-sea heat and momentum flux climatology. Int. WOCE Newslett., 24, 3-5.

Juszko, B.-A., R. F. Marsden, and S. R. Waddell, 1995: Wind stress from wave slopes using Phillips Equilibrium Theory. J. Phys. Oceanogr., 25, 185-203.

Katsaros, K. B., 1996: Satellite observations related to air-sea flux estimates. Proc. WCRP Workshop on Air-Sea Flux Fields for Forcing Ocean Models and Validating GCMs. Reading, UK, ECMWF, WCRP-95, WMO/TD-No.762, 42-52.

- M. A. Donelan, and W. M. Drennan, 1993: Flux measurements from a SWATH ship in SWADE. J. Mar. Sys., 4, 117-132.

Kaufeld, L., 1981: The development of a new Beaufort equivalent scale. Meteor. Rundsch., 34, 17-23.

Khandekar, M. L., R. Lalbeharry, and V. Cardone, 1994: The performance of the Canadian ocean-wave model (CSOWM) during the Grand Banks ERS-1 SAR Wave Spectra Validation Experiment. Atmos.-Ocean, 32, 31-60.

Kent, E. C., and P. K. Taylor, 1995: A comparison of sensible and latent heat flux estimates for the North Atlantic Ocean. J. Phys. Oceanogr., 25, 1530-1549.

_ and - 1997: Choice of a Beaufort equivalent scale. J. Atmos. Oceanic Technol., 14, 228-242.
B. S. Truscott, and J, S. Hopkins, 1993. The accuracy of voluntary observing ships' meteorological observations-results of the VSOP-NA. J. Atmos. Oceanic Technol., 10, 591608.

Kitaigorodskii, S. A., 1973: The Physics of Air-Sea Interaction. Israel Program for Scientific Translations, $237 \mathrm{pp}$.

Korevaar, C. G., 1990: North Sea Climate Based on Observations from Ships and Lightvessels. Kluwer Academic, $137 \mathrm{pp}$.

Kushnir, Y., 1994: Interdecadal variations in North Atlantic sea surface temperature and associated atmospheric conditions. J. Climate, $7,142-157$

Large, W. G., and S. Pond, 1981: Open ocean momentum flux measurements in moderate to strong winds. J. Phys. Oceanogr., 11, 324-336.

Legler, D., 1991: Errors in five-day mean surface wind and temperature conditions due to inadequate sampling. J. Atmos. Oceanic Technol., 8, 705-712.

Levitus, S., 1987: Meridional Ekman heat flux for the World Ocean and individual ocean basins. J. Phys. Oceanogr., 17, 484-492.

- 1988: Ekman volume fluxes for the World Ocean and individual ocean basins. J. Phys. Oceanogr., 18, 271-279.

Lindau, R., 1995: A new Beaufort equivalent scale. Proc. Int. COADS Winds Workshop, Kiel, Germany, Diaz and H.-J. Isemer, Eds., NOAA-ERL, IFM (Kiel), 232-252.

— , H.-J. Isemer, and L. Hasse, 1990: Towards time-dependent calibration of historical wind observations at sea. Trop. OceanAtmos. Newslett., 54, 7-12.

Mognard, N. M., W. J. Campbell, R. E. Cheney, and J. G. Marsh, 1983: Southern Ocean mean monthly waves and surface winds for winter 1978 by SEASAT radar altimeter. J. Geophys. Res., 88(C3), 1736-1744.

Naval Oceanography Command Detachment, 1981: U.S. Navy Marine Climatic Atlas of the World. U.S. Navy, 169 pp.

NCAR, 1993: Comprehensive Ocean-Atmosphere Data Set (COADS): Long marine reports/Fixed marine reports (LMR.6/ LMRF.6). Release 1a Documentation. [Available from NCAR, Boulder CO, 80307.]

Neu, H. J. A., 1984: Interannual variations and longer-term changes in the sea state of the North Atlantic from 1970 to 1982. J. Geophys. Res., 89, 6397-6402.

Oberhuber, J. M., 1988: An Atlas Based on COADS Data Set: The Budget of Heat, Buoyancy and Turbulent Kinetic Energy at the Surface of the global ocean. MPI für Met. Rep. No. 15, 199 pp. [Available from Max-Planck Institut für Meteorologie, Hamburg, Germany.]

Ochi, M. K., 1978: Wave statistics for the design of ships and offshore structures. Proc. SNAME, New York, NY, Science in Naval Architecture and Marine Environment, 47-76.

Paskausky, D., J. D. Elms, R. G. Baldwin, P. L. Franks, C. N. Williams, and K. G. Zimmerman, 1984: Addendum to Wind and Wave Summaries for Selected U.S. Coast Guard Operating Areas. NCDC NOAA, 523 pp.

Perrie, W., and B. Toulany, 1990: Fetch relations for wind generated waves, as a function of wind stress scaling. J. Phys. Oceanogr., 20, 1666-1681.

- and L. Wang, 1995: A coupling mechanism for wind and waves. J. Phys. Oceanogr., 25, 615-630.

Peterson, E. W., and L. Hasse, 1987: Did the Beaufort scale or the wind climate change? J. Phys. Oceanogr., 17, 1071-1074.

Preisendorfer, R. W., and C. D. Mobley, 1986: Albedo and glitter patterns of a wind-roughed sea surface. J. Phys. Oceanogr., 16, $1293-1316$.

Ramage, C. S., 1984: Can shipboard measurements reveal secular changes in tropical air-sea heat flux? J. Climate Appl. Meteor., 23, 187-193.

Rodewald, M., 1972: Long-term variations of the sea temperature in the area of the nine North Atlantic Ocean weather stations during the period 1951-1968. Rapp.Proc. Verbaux Reunions ICES, 162, 139-153.

Rye, H., 1976: Long-term changes in the North Sea wave climate 
and their importance for the extreme wave predictions. Mar. Sci. Commun., 2, 420-488.

Slutz, R. J., S. J. Lubker, J. D. Hiscox, S. D. Woodroof, R. L. Jenne, D. H. Joseph, P. M. Steurer, and J. D. Elms, 1985: Comprehensive Ocean-Atmosphere Data Set: Release 1. NOAA Environ. Res. Lab., CRP, 268 pp.

Smith, S. D., 1980: Wind stress and heat flux over the ocean in gale force winds. J. Phys. Oceanogr., 10, 709-726.

—_ 1988: Coefficients for sea surface wind stress, heat flux, and wind profiles as a function of wind speed and temperature. $J$. Geophys. Res., 93, 15 467-15 472.

— 1991: Some early results of the Humidity Exchange over the Sea Main Experiment. Deep Convection and Deep Water Formation in the Oceans, P. C. Chu and J. C. Gascard, Eds., Elsevier Science, 377-382.

—, R. Anderson, W. A. Oost, C. Kraan, N. Maat, J. DeCosmo, K. Katsaros, K. L. Davidson, K. Bumke, L. Hasse, and H. M. Chardwick, 1992: Sea surface wind stress and drag coefficients: The HEXOS results. Bound.-Layer. Meteor., 60, 109-142.

Srokosz, M. A., and P. G. Challenor, 1987: Joint distribution of wave height and period: A critical comparison. Ocean Eng., 14, 295311.

Toba, Y., N. Iida, H. Kawamura, N. Ebuchi, and I. S. F. Jones, 1990: Wave dependence of sea surface wind stress. J. Phys. Oceanogr., 20, 705-721.

Tournadre, J., and R. Ezraty, 1990: Local climatology of wind and sea state by means of satellite radar altimeter measurements. $J$. Geophys. Res., 95, 18 225-18 268.

U.S. Navy, 1983: United States Navy Spectral Ocean Wave Model Climatic Atlas: North Atlantic Ocean. Naval Oceanography Command Detachment, $373 \mathrm{pp}$.

Walden, H., N. Hogben, M. D. Burkhart, R. Dorrestein, W. H. Warnsink, and Y. Yamanouchi, 1970: Long term variability. Fourth
Int. Ship Structure Congress, Tokyo, Japan, Royal Institute of Naval Architecture, 49-59.

Ward, M. N., 1992: Provisionally corrected surface wind data, worldwide ocean-atmosphere surface fields, and Sahelian rainfall variability. J. Climate, 5, 454-475.

Weare, B. C., 1989: Uncertainties in estimates of surface heat fluxes derived from marine reports over the tropical and subtropical oceans. Tellus, 41A, 357-370.

_ calculated monthly mean oceanic surface heat fluxes. Tellus, 33, 211-224.

Weber, S. L., 1994: Statistics of the air-sea fluxes of momentum and mechanical energy in a coupled wave-atmosphere model. $J$. Phys. Oceanogr., 24, 1388-1398.

- H. von Storch, P. Viterbo, and L. Zambresky, 1993: Coupling and ocean wave model to an atmospheric general circulation model. Climate Dyn. 9, 63-69.

Wilkerson, J. C., and M. D. Earle, 1990: A study of differences between environmental reports by ships in the voluntary observing program and measurements from NOAA/buoys. J. Geophys. Res., 95, 3373-3385.

WMO, 1970: The Beaufort scale wind force. Reports on Marine Science Affairs Rep. 3, WMO, 22 pp. [Available from World Meteorological Organization, Case Postale 2300, CH-1211 Geneva 2 , Switzerland.]

— 1990: International list of selected, supplementary and auxiliary ships. WMO-47, World Meteorological Organization.

Woodruff, S. D., S. J. Lubker, K. Wolter, S. J. Worley, and J. D. Elms, 1993: Comprehensive Ocean-Atmosphere Data Set (COADS) Release 1a: 1980-92. Earth Sys. Monitor, 4, No. 1, $1-8$.

Yelland, M., and P. K. Taylor, 1996: Wind stress measurements from the open ocean. J. Phys. Oceanogr., 26, 1712-1733.

Young, I., and G. Holland, 1995: Atlas of the Oceans: Wind and Wave Climate. Elsevier-Pergamon, 246 pp. 